\title{
Systematic design approach to the development of high-strength, locally adapted structures with the aid of the finite element design (FED) method
}

\author{
Armin Lohrengel ${ }^{1, a}$, Volker Wesling ${ }^{2, b}$, Günter Schäfer ${ }^{1, a}$, Antonia Schram ${ }^{2, b}$ \\ Sara Bessling ${ }^{1, a}$, Pierre Echtermeyer ${ }^{2, b}$ and Konrad Stahr ${ }^{1, a}$ \\ ${ }^{1}$ Institute of Mechanical Engineering (IMW), Technische Universität Clausthal (TUC) \\ Robert-Koch-Straße 32, 38678 Clausthal-Zellerfeld, Germany \\ ${ }^{2}$ Institute of Welding and Machining (ISAF), Technische Universität Clausthal (TUC), \\ Agricolastraße 2, 38678 Clausthal-Zellerfeld, Germany \\ ainfo@imw.tu-clausthal.de, boffice@isaf.tu-clausthal.de
}

\begin{abstract}
Keywords: design-process, design methodology, multi-material design, requirement optimization, mixed construction, material properties, local material properties
\end{abstract}

\begin{abstract}
Design engineers can choose from a large variety of materials in order to fulfill a certain function. In those fields of application with a lower level of complexity, it is often sufficient to manufacture the entire component in a "monolithic" manner from one single material. Concurrent, partly contradictory and, most probably, local requirements that must be fulfilled by a component often make material selection more difficult. As a consequence, it is often necessary to use several different materials with a local and functional orientation, which is a part of the multi-material design strategy. The potential of different materials can be used most effectively if this information is made available to the design engineers as early on in the design process as possible. The aim of the SFB 675 sub-project C7, therefore, is the development of a systematic design approach (Finite Element Design, FED) that focuses on finite component elements. As a result, the potential of the optimization of local properties is taken into consideration, and the interaction between the materials, production processes, and design can all be described.
\end{abstract}

\section{Introduction}

Since, at present, the material is not considered until a relatively late stage during the systematic design process in accordance with VDI 2221, it is often impossible to fully benefit from the potential of the materials. In addition, certain requirements only apply to specific local areas of a component. The implementation of the multi-material design concept, which includes the selection of materials and material combinations based on local stress factors, enables significant cost and weight savings effects within a design project [1]. This, however, requires a systematic approach that ensures the holistic consideration of the design, material properties, and manufacturing processes [2]. For the time being, approaches that simultaneously consider the design, local material properties, and production processes in one systematic design concept are not described in the literature.

The aim is to develop a systematic design approach for the development of high-strength, locally adapted structures with the aid of the finite element design (FED) [3]. Based on the conceptual design phase of the design process in accordance with VDI 2221, the transition towards the FED system takes place as shown in Fig. 1. The basic solution that is formulated during the conceptual design phase is the starting point of the FED system and runs parallel with VDI 2221 as an iterative process. 


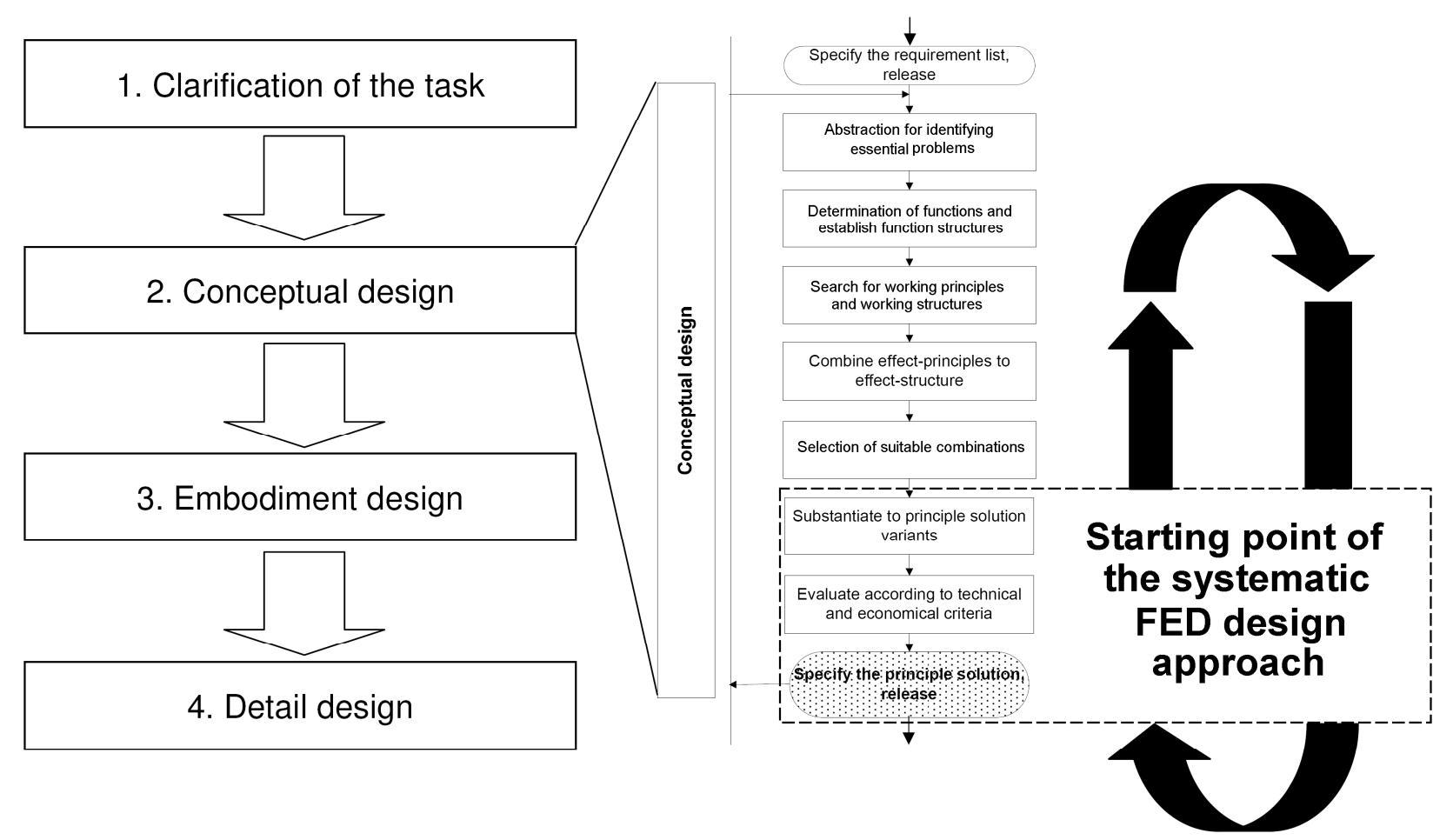

Fig. 1: Integration of the FED system into the conceptual design phase in accordance with VDI 2221

The finite element design is used to develop a systematic design approach that enables the local consideration of a design. The overall structure is divided into local (finite) sub-structures (elements) that are then classified based on their respective requirements. Unlike in the case of the finite element method (FEM), the stress of the component is not determined numerically. Instead, the optimum material and manufacturing process are selected based on the local requirements that are placed on the finite elements.

\section{State of the art}

Systematic design approach and material selection. Increasing demands concerning a materialoriented design, accompanied by the obligation to save resources and improve the quality, require a systematic computer-integrated design method, an effective material, and manufacturing process selection.

A general method for the development and design of technical products is suggested in the wellknown VDI guideline 2221 [4]. Following this classical point of view, material selection does not take place until during the embodiment design phase so that it is based on a fixed technical solution suggestion. As a result, the mutual influence of the technology, material, and design cannot be taken into consideration to a sufficient extent [5]. In addition, this method requires numerous timeconsuming iteration steps so that, on the whole, the result may in fact not represent the optimum technical solution [6].

In contrast to this, the integration of the material selection into the conceptual design phase enables the design engineer to make full use of the potential of the material and manufacturing options and, in turn, to realize product innovations [7]. This approach supports the design of innovative products, since extensive knowledge concerning the material and manufacturing process can be integrated into the product development [8]. The unity between the material, shape, and manufacturing process is supported by the early integration of the material selection with the aim to achieve the optimum holistic technical solution in view of the design, manufacturing process, and use of the component [6]. 
During the design process, material selection usually restricts itself to materials that are already used or to similar materials in order to minimize the product risk from a material point of view. As a result, material changes normally only take place within a family or group of materials. The selection of a new material is only taken into consideration if this may improve the product properties or the economic efficiency of the manufacturing process [6].

According to [6], the material selection process - just as the design process - follows the steps of the VDI guideline 2221. The individual phases are as follows:

\section{Clarification of the task}

- Determination of the material requirements including the analysis of all the influencing factors

- Specification of the technical and economic requirements

- $\quad$ The result is a material requirements list

\section{Conceptual design phase}

- Pre-selection of the suitable materials and verification of the congruence between the material requirements and the characteristic property profile of the pre-selected materials

- The result is a list of possible materials

III. Embodiment design phase

- Fine selection and assessment; differentiation of the possible materials via a weighted evaluation

- The result is a list of test materials

\section{Detail design phase}

- Evaluation of the test materials and the determination of the component requirements

- Making a decision while taking the technological and form design factors into consideration

- The result is a basis for making a decision

The successful material selection in this sense requires a methodical approach, e.g. following the simultaneous engineering concept [9].

The complete clarification concerning the potential use of certain materials invariably requires an analysis of all of their properties, while the actual material selection itself is always a compromise [8]. The selection of materials is very time-consuming, expensive, and requires a lot of personnel, since up-to-date knowledge concerning potential materials and manufacturing processes are of the utmost importance. In order to be able to make the fullest use possible of the material and manufacturing potential, the design engineer needs as much information as possible [10].

Based on the component requirements, the material requirements can be deduced, which play an important part in enabling the component to fulfill its purpose. The definition of the material requirements becomes increasingly precise while the concrete from of the technical products becomes clearer. The number of possible materials thereby decreases. The material selection must also take the manufacturing conditions into consideration, which might require adaptations in the form of new processes. $/ 9$ /

The monolithic component design approach does not meet the requirements in terms of a lightweight construction if the stress on the component is complex and inhomogeneous. In addition, it also makes material selection more difficult, since contradicting requirements, such as a high level of strength and hardness paired with a high level of ductility, are only rarely fulfilled by common design materials [7]; [10]. The creation of customized material properties for these requirements is, therefore, desirable. Mixed and multi-material design approaches enable the use of different materials or material combinations in different areas. New materials and manufacturing technologies offer the necessary design freedom. It is also always possible to achieve the overall 
adaptation of properties via the local adaptation of the properties of a material. The material properties should be combined in such a way that their characteristic properties profile matches the material requirements profile to the highest possible extent [10].

In view of the required use of materials with a local and functional orientation in accordance with the multi-material design strategy, the matching of the requirements and properties with the current material selection procedures proves difficult. Holistic selection methods, e.g. in accordance with Ashby [11] and with the aid of application-specific material indices and diagrams, or in accordance with Dargie [12] and with the aid of suitability matrices concerning the material and manufacturing process selection, either lead to the premature elimination of potential material solutions or their level of differentiation is not fine enough for the material requirements profile that is to be defined. Regarding a methodical material selection the technical designer experiences no considerable support at present.

The manufacturing technology has a major impact on the component design so that design-related restrictions must be taken into consideration for the selection of certain manufacturing processes. During the manufacturing process, the assumed mechanical properties may be changed drastically, e.g. through welding or machining, which in turn may cause the component to fail [6].

Computer-assisted material selection. At present, information technology enables PC and Internet-based solutions for material selection. A finer sub-classification can be achieved with the aid of material databases, higher information systems, and expert systems.

Examples of current material databases are Matweb or Metals Infobase, although the support for the design engineer in selecting a material is mainly based on the determination of characteristic values that are based on value ranges that must be explicitly stated. The link between the design requirements and these characteristic material values still has not been established in a holistic or computer-assisted manner. The use and combination of existing material databases for informational purposes and the determination of suitable steels based on predefined material requirements (e.g. hardness values or manufacturing processes) in accordance with [13] is an improvement, however. Consulting and combining existing material data bases for the acquisition of information as well as the determination of suitable steel on the basis of given requirements (e.g. strength or manufacturing method) to the material according to [13] represents an improvement for this already.

As far as higher information systems are concerned, the CES Selector by Granta Design, for example, is the current state of the art. However, in this case, too, the materials are selected in a computer-assisted manner based on explicit value ranges and/or with the aid of two graphical methods of elimination in several steps, which is an implementation of the methods described by Ashby [11]. Local considerations within the framework of a multi-material design and the corresponding material selection are currently not supported by any of the material databases or higher information systems.

The so-called expert systems, in which the system presents itself as the expert and enters into a dialog with the user in order to find a solution, have not gained general acceptance yet, which is due to their failure to reflect the complex interrelations between the design, material, and manufacturing process considerations during the material selection process [6]

Dissimilar materials. The implementation of a material-oriented design process, in which the materials are selected based on local stress considerations, leads to significant cost and weight savings, as has already been demonstrated by the multi-material design approach in the automotive industry [1].

Dissimilar joints can be produced in various manners, i.e. by force fit, form fit, or material joining. For the characterization of material combinations, a first approximation is the classification as to whether they are of the same, similar, or dissimilar type [14]. Dissimilar materials with their different crystal structures and physical properties have a major impact on the welding task. Apart from these physical factors, the weldability of a combination of dissimilar materials also depends on the welding method utilized. Fusion welding leads to new alloys that consist of the parent materials 
and of the filler material, if used. Pressure welding, on the other hand, does not lead to a common melt of the involved materials so that intermetallic phases are avoided to a large extent.

If the filler materials produce the required properties only insufficiently, buffer layers can be used in order to compensate for extremely different material properties. Buffer layers may also prevent unwanted intermetallic phases and compensate for different melting temperatures and thermal expansion coefficients. Another method for compensating for different material properties is the use of transition pieces or adaptors. These elements usually have a combination of dissimilar materials at their center, and their two free ends are welded to materials of their respective same type, e.g. in a production line.

The joining technology must guarantee a permanent and reliable joint of these materials, in which the selection of the most suitable method depends on the metallurgical compatibility of the materials involved. One can use material-based thermal processes, such as welding or hightemperature brazing, sometimes also adhesive bonding, or force-fitting mechanical process, such as clinching. The process selection is based on the material, especially when it comes to the joining of property-optimized designs, e.g. of tailored blanks or hydroformed elements [15]. In the case of dissimilar material joints, the process selection is always a compromise, since the selection can be made in an optimal manner only for one, or even for none, of the materials involved [16].

Thermal processes often offer the advantage of a high level of design freedom, combined with a high economic efficiency for single units as well as for the mass production [17]. If there is a risk of intermetallic brittle phases due to the metallurgical incompatibility of the materials involved, one can use high-temperature brazing, friction, or pressure welding processes since, in these cases, the occurrence of brittle phases can be suppressed or reduced, or the brittle phases can be eliminated from the joint by upsetting. As a result, thermal joining methods with the above-mentioned processspecific advantages are also available for these cases.

In the case of fusion welding processes, however, the energy input must be reduced [18], if possible, and the dilution of the welding melt must be minimized in order to ensure that the weld deposit has the required properties of the parent material to the largest possible extent [16]. If a filler material is necessary for process-related or metallurgical reasons, it must be selected with the aid of a Schaeffler diagram in the case of dissimilar joints involving at least one high-alloy steel. Blackand-white joints are material combinations of stainless high-alloy and low-alloy steels and can often be found in power plant and general plant engineering. They are the most common welded material combinations and can be subdivided into several stress groups, depending on their areas of application, so that the welding process must be adapted accordingly [16]. Their areas of application and those of corrosion-resistant steels are nearly identical. Less stringent requirements concerning corrosion resistance, however, enable the selection of less expensive materials [19].

For dissimilar joints of unalloyed and low-alloy steels, the filler material only needs to be adapted to the lower-strength material according to [14]. According to [16], the chemical composition should correspond more or less to the mean of the chemical alloy composition of the materials involved in order to minimize the diffusion of their alloying elements. The heat input must be adapted to the steel with the greater hardenability [16].

Materials, which were chosen for a material combination because of their specific properties profile, naturally show differences or so-called mismatches in their properties. One should expect different strain values under tensile stress as well as different ductility and hardness values as far as the mechanical and technological properties are concerned. The joining problems involved with dissimilar joints are due to the mechanical, physical, and chemical property differences.

The required joining energy for welding is determined by the thermal conductivity and melting range/temperature, among other things, so that the heat input must be adapted to the materials involved. Apart from metallurgical compatibility, these material-physical properties of the materials must also be taken into consideration.

Determination of the local material properties. The description of the local properties of materially joined dissimilar materials requires measurement methods that enable the precise 
characterization of the joining zone and the adjacent zones. The possible methods for this are the determination of hardness distributions, photos of the material structures, and local strain measurements (ESPI).

The stress that is put on a component, or component area, and its ability to cope with this stress in turn form the basis for its design. This requires knowledge concerning the stress distribution, which in turn must be considered as local stress. The stress values are preferably calculated with the aid of measured strain values. Strain gauges and the electronic speckle pattern interferometry (ESPI) are both possible methods to be used for local strain measurements. Compared to strain gauges, ESPI systems are easier and more flexible to use, since they do not require any complicated calibration or temperature compensation, which in turn significantly reduces the preparation time [20]; [21]. In terms of local strain values, strain gauges are limited to their contact surface. The basis of ESPI measurements is the measurement of dislocations and, thereby, the identification of deformations of the component surfaces [22].

An example of the industrial application of this method is the measurement of the deformations of component areas or entire components with the aid of ESPI if the deformations were caused by mechanical stress. Various different measuring systems, which vary in size and their measuring range, enable the identification of the critical component areas in complex structures [23].

Recent scientific studies have dealt with the determination of material properties with the aid of ESPI as well as with the ways to influence and characterize them in a targeted manner. The main focus is the determination of the modulus of elasticity of various materials. This is inferred from the determined strain values that are combined with the stress and the specimen cross-section. The considered material spectrum ranges from rubber materials [24], via wood [25], to aluminum structures [26]. Apart from the characterization of material properties, the literature also includes the ESPI studies of joined components. In [27] and [28], the deformation behavior of welded blanks was determined. Although the mean value of the modulus of elasticity over the entire specimen area is usually determined, [29] presents the modulus of elasticity of a WIG-welded seam consisting of Ti6242 (TiAl6Sn2Zr4Mo2).

Apart from the determination of the characteristic material values, the literature also provides information concerning the local strains and stresses of contoured components. [30] and [31] document the laser-optical strain measurements of high-frequency welded, contoured components made of the sheet metal material 1.0338 (DC04). Recent ESPI studies of contoured components are described in [32]. For example, examinations concerning local stress were performed on a dental bridge.

If one uses the ESPI deformation measurement in conjunction with the finite element method, it is possible to determine the general and residual stress conditions on component surfaces, which are caused by elastic-plastic stress. [33] 


\section{Systematic FED design approach}

Component structuring. In order to identify the optimum local material solution in accordance with the multi-material design strategy, the component must be differentiated into finite areas. The finite element design is a so-called top-down method as it starts with a global view, followed by the increasing concretization from the top downwards. An overall problem - in this case the design unit - is separated into sub-problems, which can be further separated into even smaller sub-problems. The solution is found in the course of this process by taking into consideration the local requirements that the respective sub-areas of the design unit must fulfill.

The input of the systematic FED design approach is the output of the conceptual design phase (compare Fig. 1). In accordance with the VDI guideline 2221, the conceptual design phase follows the clarification of the specific task, and includes the respective abstraction into the main problems, definition of the function structures, and search for suitable active principles and their combination in an active structure in order to specify the principle solution [34]. This means that the conceptual design is the principle specification of a solution. This principle solution is then divided into areas with different functions. The basis for this particular process is the previously defined function structure. This function structure provides information concerning a possible or useful order and the interconnection of the sub-functions from a logic and/or physical point of view.

The requirements that must be fulfilled by the local areas result from the consideration of the local functions. This consideration of local requirements in view of the assignment of the required local material properties, however, requires the structuring of the entire component. The total, overall component is differentiated into functional elements and interfaces. The functional elements are those areas of the component that must fulfill specific requirements. Interfaces are used to describe the interconnection between the various functional elements. The torque conducting structure that is shown in Fig. 2 is an example of the fundamental idea of the component structuring method.

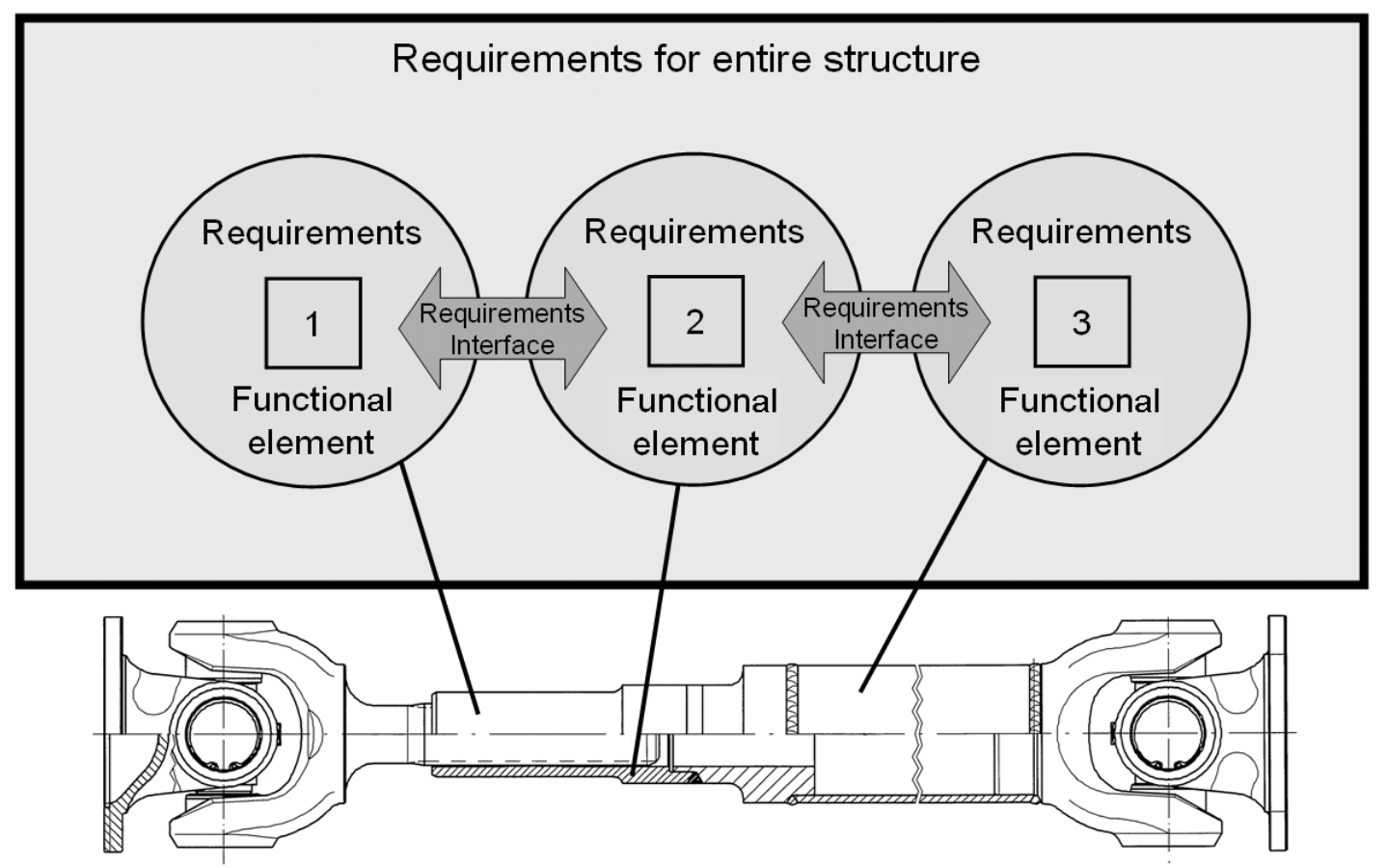

Fig. 2: Structuring the principle solution in overall structure, functional elements, and interfaces

One detail of the overall component structure of a drive shaft has been subdivided into the functional elements 1 to 3 . Each of the functional elements is characterized by specific requirements that provide a localized view of the essential component functions. The relative movement between the functional elements 1 and 2 is described by the interface. The interface is used, for example, to 
describe the requirements concerning the wear as well as the resulting required local material properties. The interface, which is located between the functional elements 2 and 3, for example, explains the need for a material joint. The interface definition includes certain material properties that are closely connected to the joining process and the resulting properties of the joint. Fig. 3 shows a schematic diagram of the reference process of the systematic FED design approach, which is based on targeted questions.

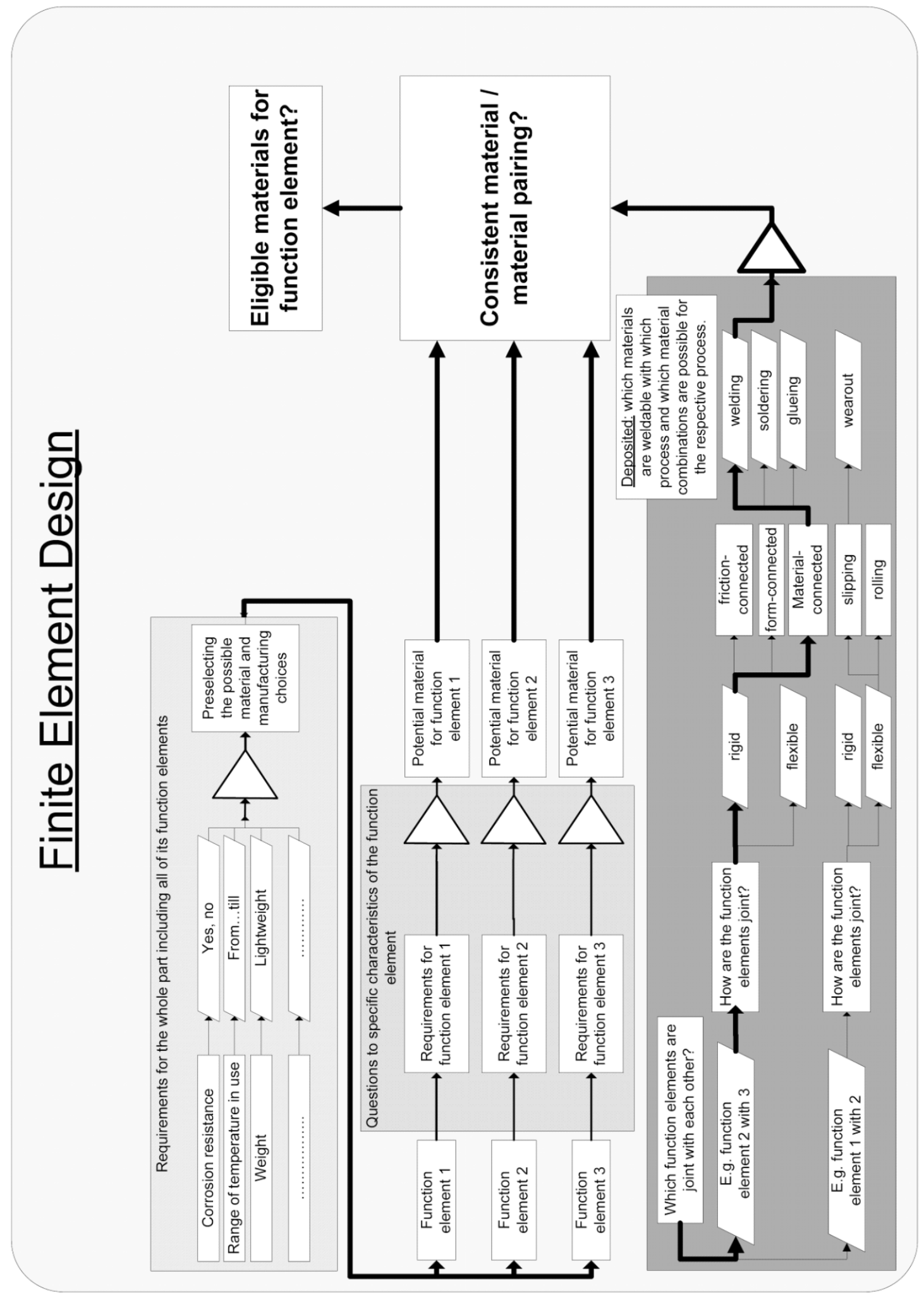

Fig. 3: Schematic process of the systematic FED design approach 
Product and material requirements. The abovementioned structuring of the component into functional elements and interfaces is the basis of the material selection process within the systematic FED design approach. Targeted questions concerning the entire component, functional elements, and interfaces enable the specification of localized requirement matrices. The questions, concerning the entire component, are of a general nature. They result, for example, from the restrictions of a requirements list that forms the basis of the design. This requirements list is usually a preliminary stage in the determination of the material requirements. Requirements can be divided into properties that the material should have, as well as into conditions that it should fulfill, and they must be classified as fixed requirements, minimum requirements, or desires. The basis for the formulation of the requirements is formed by the general product and component requirements, but also by those guidelines concerning the major characteristic features, association lists, checklists, requirement catalogs, search matrices, electronic lists of characteristics, or similar tools [34]. In addition, the abstraction of the determined functions, which was performed during the conceptual design phase, or a function structure, can also be used as the working basis.

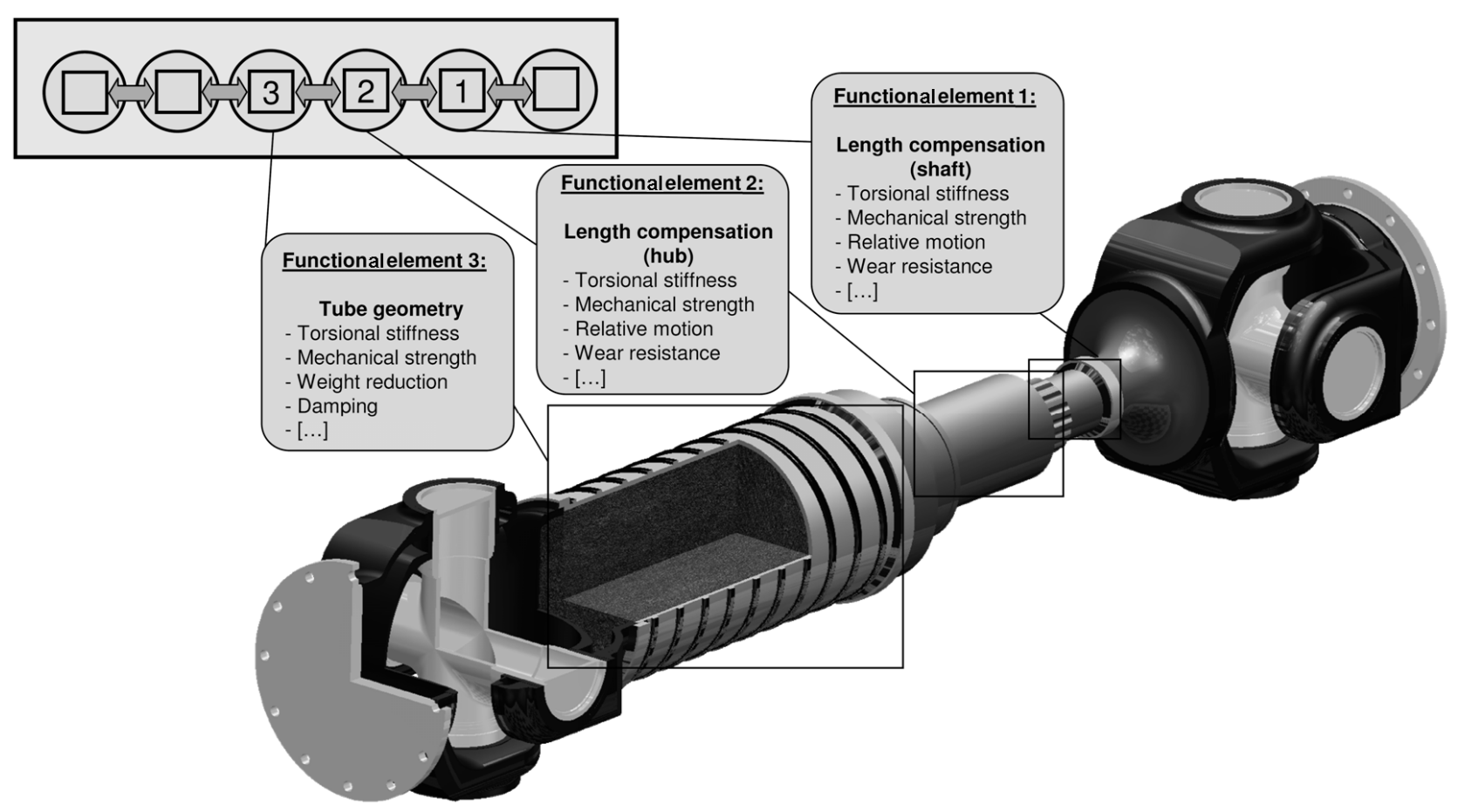

Fig. 4: Material requirements of the functional element that are implied by local requirements

An existing function structure can be used to define the sub-functions of the functional elements, which then define the local requirements that in turn form the material requirements profile of the functional element. During the search for suitable materials for a component, these local component requirements must be translated into material requirements. Fig. 4 describes the specification of a functional element based on the material requirements that are implied by the local requirements. The required material properties, i.e. implied material properties, can be assigned directly or indirectly to the requirement matrices that are to be drawn up in the further course of the process. Identified local material requirements and their properties form the basis of the material selection process for an individual functional element. The sensible reduction of functional contents to component requirements and, thereby, material requirements serves as initial support for an easy and reliable local material selection.

The sub-functions of the individual functional elements and the accompanying material requirements lead to the required material properties. These properties (compare Fig. 5) and their property values are used for the reduction of the entire material spectrum that is available based on 
an assessment. This is done with the aid of quantitative and qualitative material properties, which are used for database enquiries.

The priority of the enquiry and assessment of an existing data pool is to identify those materials that match the requirement matrices, which were established based on local functional elements, as well as the property profiles of potential engineering materials to the highest possible extent.

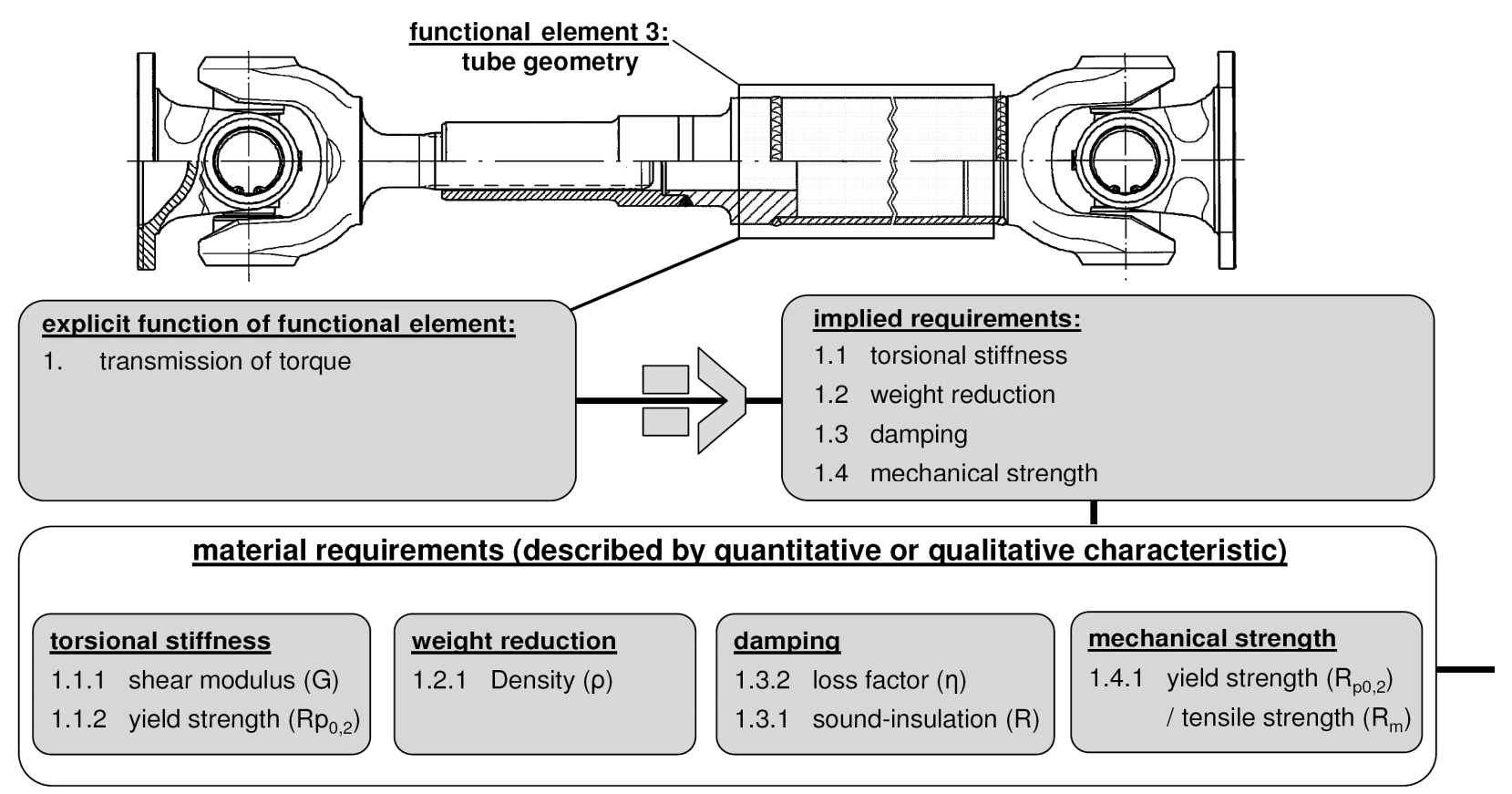

Fig. 5: Differentiation of explicit functions into implicit material requirements

A very important step in the abovementioned process is the necessary differentiation of the design requirements in terms of the associated material requirements. At present, this step is not supported by any of the existing material databases, higher information systems, or even expert systems, and the literature only describes it as an example. Material databases and material diagrams according to [11] only enable the identification of material groups, families, and types that comply with the desired values ranges of specific properties, or the visual comparison of one or two properties of different materials.

The aim, therefore, is to deduce the product and design requirements with a strong and extensive focus on the material requirements. Only these properties enable the enquiry of the existing material databases and, thereby, the integration of materials into the conceptual design phase as well as a requirement-driven material selection.

Müller [35] defines a lexical and semantical classification of the product requirements. Lütkepohl [36] extends this classification model by the material factor in order to enable the identification and classification of the material requirements and their effective and efficient use throughout the solution-finding process. This system for an intelligent requirement analysis, and certain selection criteria, can be used to filter the requirements. After the start of a search request, the requirements list will be browsed by the software agent and the requirements will be identified and analyzed. For material-oriented requirements, the corresponding search criteria must be entered into the system in order to obtain a list of requirements with a reference to materials. The materialoriented requirements that are identified as a result of this process can then be used for the materialoriented design process in accordance with a suggestion defined by [36].

For the quality evaluation of the material requirements that were identified, certain quality criteria in terms of the requirements and requirement documents must be used according to [37] and [38]. High-quality requirements are characterized by atomicity, identifiability, comprehensibility, unambiguousness, relevance, and completeness. 
In order to enable an effective material selection, the material requirements must be described by qualitative and, if possible, quantitative properties. The design engineer can retrieve material properties from various databases and information systems but there is usually a strong discrepancy between the function-oriented requirements and the mostly physical/chemical properties of the materials. In a first step, it is necessary to establish a connection between the functional requirements and material properties. These connections, however, are often highly complex and in most cases it is even impossible to describe them in a clear manner. A clear material-oriented description of a requirement may, in most cases, require several requirement or material characteristics and their degree of fulfillment in view of a target function that must be assessed.

Comparison and assessment of material solutions. The decisive factor for the assessment of a potential material in view of its function fulfillment is the degree of matching between the requirements and properties profile. The assessment that must be performed in the course of the material selection process is mainly aimed at an objective, function-oriented comparison of various potential solutions rather than at determining the degree of approximation to an intended ideal solution. The quantitative and variable assessment is performed in order to generate and maintain a dynamic list of potential material solutions in the course of the entire FED reference process.

In view of the intended multi-material design, however, existing holistic and insufficiently differentiated material selection methods, e.g. with the aid of graphical methods according to Ashby [11] or in accordance with the VDI guideline 2225, are unrewarding. Instead, an assessment method, which takes numerous targets and the properties that are in turn necessary for the function fulfillment into consideration, is required. The targets are defined based on the requirements and restrictions of the sub-functions of the functional elements, while the properties are defined based on the characteristics of the potential engineering material.

In order to do justice to the varying importance of the material requirements and to an adequate comparison of the requirements and properties profiles, a suitable assessment method must be applied. The assessment criteria must be directly connected to the various sub-requirements. An adequate method for the quantitative assessment of the degree of matching of the material requirements and properties profiles is the value-benefit analysis.

A first step of this assessment method is the formulation of targets, which then form the basis for the criteria for the assessment of solution variants. A function target must be deduced in such a manner that it leads to criteria (target contributions) that can be measured or estimated. This is the only way to calculate the benefit with the aid of the determined influencing variables (characteristic numbers). The described differentiation of explicit functions or requirements into implicit material requirements (compare Fig. 5), thereby, forms the basis for the definition of a required target system (compare Fig. 6). These types of target systems with a decreasing level of complexity in the vertical direction and a horizontal organization of the functional elements can be defined for the entire design unit and form the basis for the next steps.

The requirement matrices, which were defined beforehand through specific questions concerning the design unit, are transferred into the target matrix. 


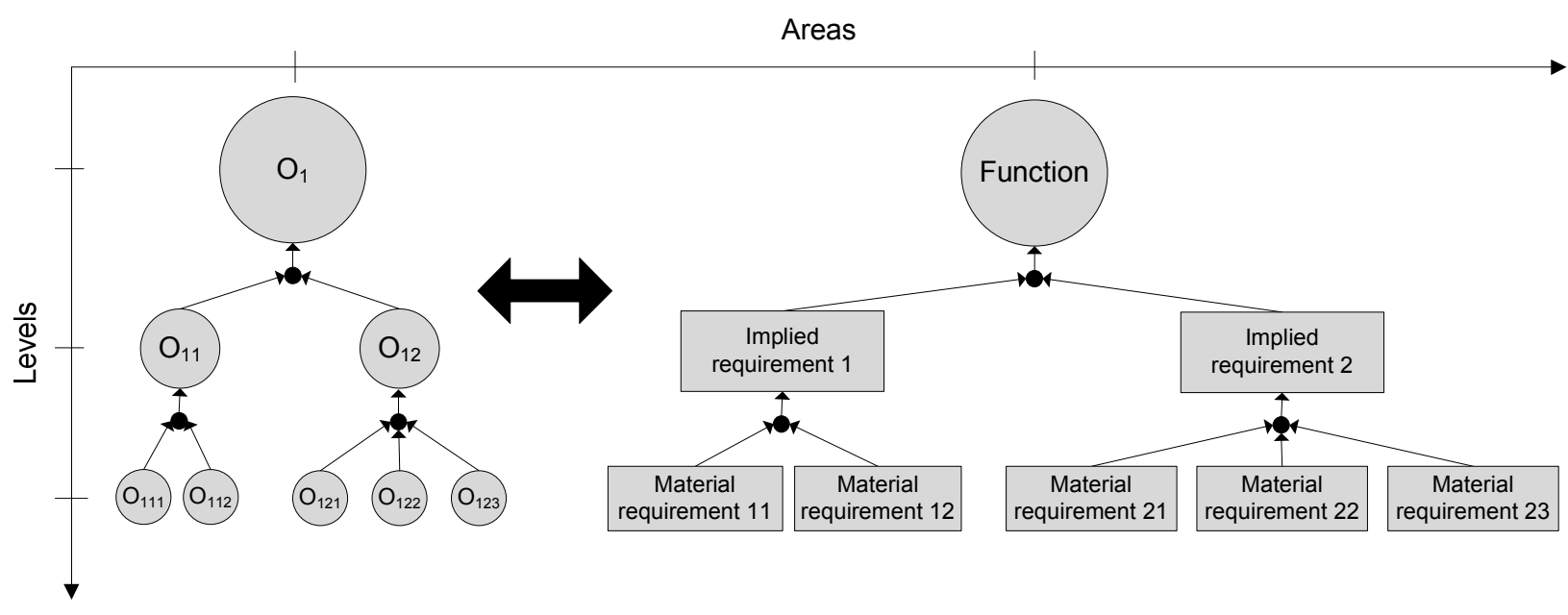

Fig. 6: Structuring of a functional element and definition of a target system via the sub-division into functions, requirements and material requirements

In this sense, a target idea usually comprises several targets and sub-targets with a hierarchical structure. According to [34], [37], and [38], the definition of sub-targets on the third structuring level must be performed while taking the completeness, mutual independence, and qualitative/quantitative ability to be assessed into consideration. It might be possible, though, that several of the various material properties are mutually dependent so that often the criterion of the mutual independence of the sub-targets cannot be fulfilled during the material selection process.

For the determination of the degree of fulfillment of a function target, requirements are used as sub-targets that must be fulfilled, while the material requirements and the associated properties serve as the assessment characteristics since they are essential for the function fulfillment of the functional element. One must use certain assessment criteria and weight their importance for the function fulfillment. Direct weighting, absolute weighting, or the comparison in pairs according to [6] and [34] are possible methods for this purpose, but one must also verify as to whether they can be represented in the software implementation of the systematic FED design approach. Fig. 7 shows exemplarily the assignment of properties to assessment criteria on functional element 3 (compare Fig. 5 and 6) and its local requirements. The target criteria are quantified by target values. According to [6], the degree of fulfillment of a target criterion is determined with the aid of known material indices based on characteristic physical material values.

\begin{tabular}{|c|c|c|c|c|c|c|c|c|c|c|c|}
\hline \multirow{2}{*}{$\begin{array}{c}\text { Objective system } \\
\text { No. [o] }\end{array}$} & \multicolumn{3}{|c|}{ Evaluation criteria } & \multicolumn{3}{|c|}{ Objective Parameter(s) } & \multicolumn{3}{|c|}{ Potential material m } & \multirow[t]{2}{*}{$\ldots$} & \multirow[t]{2}{*}{ Potential material $\mathrm{n}$} \\
\hline & No. [a] & & wt $\mid$ & & & Unit & $\begin{array}{c}\text { Magnitude } \\
\mathrm{p}_{\mathrm{am}}\end{array}$ & $\begin{array}{l}\text { Value } \\
\mathrm{pam}^{*}\end{array}$ & $\begin{array}{l}\text { Weighted value } \\
\text { wp }_{a m^{*}}{ }^{*}\end{array}$ & & \\
\hline \multirow{5}{*}{$\begin{array}{c}\text { Transmission } \\
\text { of torque }\end{array}$} & 1 & Torsional stiffness & & or & $\mathrm{G} / \rho$ & & $p_{1 m}$ & $p_{1 m}{ }^{*}=\frac{p_{1 m}}{\operatorname{MAX}\left(p_{11}, p_{12}, \ldots, p_{1 n}\right)} \cdot 100[\%]$ & $p_{1 m} * w_{p 1}$ & $\ldots$ & $\ldots$ \\
\hline & 2 & Weight reduction & & er & Global $(\rho)$ & & $p_{2 m}$ & global & global & $\ldots$ & $\ldots$ \\
\hline & -3 & Damping & & or & $\eta / \rho$ & & $p_{3 m}$ & 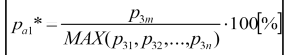 & $p_{3 m} * \cdot w_{p 3}$ & & .. \\
\hline & 4 & $\begin{array}{l}\text { Mechanical } \\
\text { strength }\end{array}$ & & 04 & $\mathrm{R}_{\mathrm{F} 0.2} / \rho$ & & $p_{4 m}$ & $p_{a 1}^{*}=\frac{p_{4 m}}{\operatorname{MAX}\left(p_{41}, p_{42}, \ldots, p_{4 n}\right)} \cdot 100[\%]$ & $p_{4 m} * w_{p 4}$ & & $\cdots$ \\
\hline & 5 & $\begin{array}{l}\text { Corrosion } \\
\text { resistance }\end{array}$ & & er & restrictive & & $p_{5 m}$ & restrictive & restrictive & ... & .. \\
\hline & & & & & & & & $P_{o m}=\sum_{i=1}^{n} p_{a m}$ & $P_{o m}=\sum_{i=1}^{n} p_{a m} * \cdot w_{p a}$ & $\ldots$ & $\cdots$ \\
\hline
\end{tabular}

Fig. 7: Correlation of the requirements and properties in the assessment matrix

Standardization of material properties. For the comparison of properties, especially in view of the software implementation of the systematic FED design approach, several adaptations of the 
known value-benefit analysis method must be performed. The varying absolute values of the properties lead to different, arbitrary weightings during the determination of the degree of fulfillment of the target and, in addition to that, the assessment direction, i.e. the question as to whether the quantitative description of an upper of lower property value is to be considered as the fulfillment of the target, is a potential error source for the assessment result. In terms of the tensile strength, for example, a high numerical value is better than a lower one, but from the point of view of a lightweight construction, a low specific density has a higher degree of fulfillment of the target.

Ways for the dimensionless standardization of property values are included in the following descriptions concerning the scaling of properties. At the start of the determination of the fulfillment degrees of the sub-function, the maximum or minimum value of a target is defined as the reference value in the data pool and the property values of the potential materials are referred to this reference value in view of the degree of fulfillment. Depending on the assessment direction, the scaled property values result from equation 1 or 2 :

$$
p_{a b} *=\frac{p_{a b}}{\operatorname{MAX}\left(p_{a 1}, p_{a 2}, \ldots, p_{a z}\right)} \cdot 100[\%]
$$

or for properties, such as costs or specific densities, in which a lower value represents a higher degree of fulfillment:

$$
p_{a b} *=\frac{\operatorname{MIN}\left(p_{a 1}, p_{a 2}, \ldots, p_{a z}\right)}{p_{a b}} \cdot 100[\%] .
$$

Every property is scaled in such a way that its highest numerical value does not exceed 100 . In the course of the assessment of database contents, only one material property at a time is considered. The highest value of this property is rated at a degree of fulfillment of 100 percent and all of the other values are scaled accordingly. After the scaling of $n$ material properties that form the basis of a requirement concerning the functional element and their weighting $w$, the material performance index $P_{r e q}$ can be determined for this requirement with the aid of equation 3:

$$
P_{r e q, n}=\sum_{i=1}^{n} p_{a b} \cdot w
$$

This assessment standard can also be used for qualitative and attributive property values. It is possible to define classes that describe the fulfillment degrees of the various property values. The material property corrosion resistance, for example, can be divided into the fulfillment degrees 1-5, i.e. into ranges between 0, 20, 40, 60, 80, and 100 percent. Attributive properties, such as the resistance against certain media (resistance table) or the operating temperature range, are digitally assessed in view of their existence similar to the Pugh method, i.e. the fulfillment degree is " 0 " or " 1 ", or 0 or 100 percent.

In general, only a generic (total component) or interstitial (interface) requirement that has been defined beforehand leads to the definite exclusion of a specific material from the subsequent solution-finding process if the requirement is not fulfilled. Fig. 8 shows the described material selection process based on the "specific questions concerning the functional elements" and, thereby, is a differentiation of Fig. 3. 


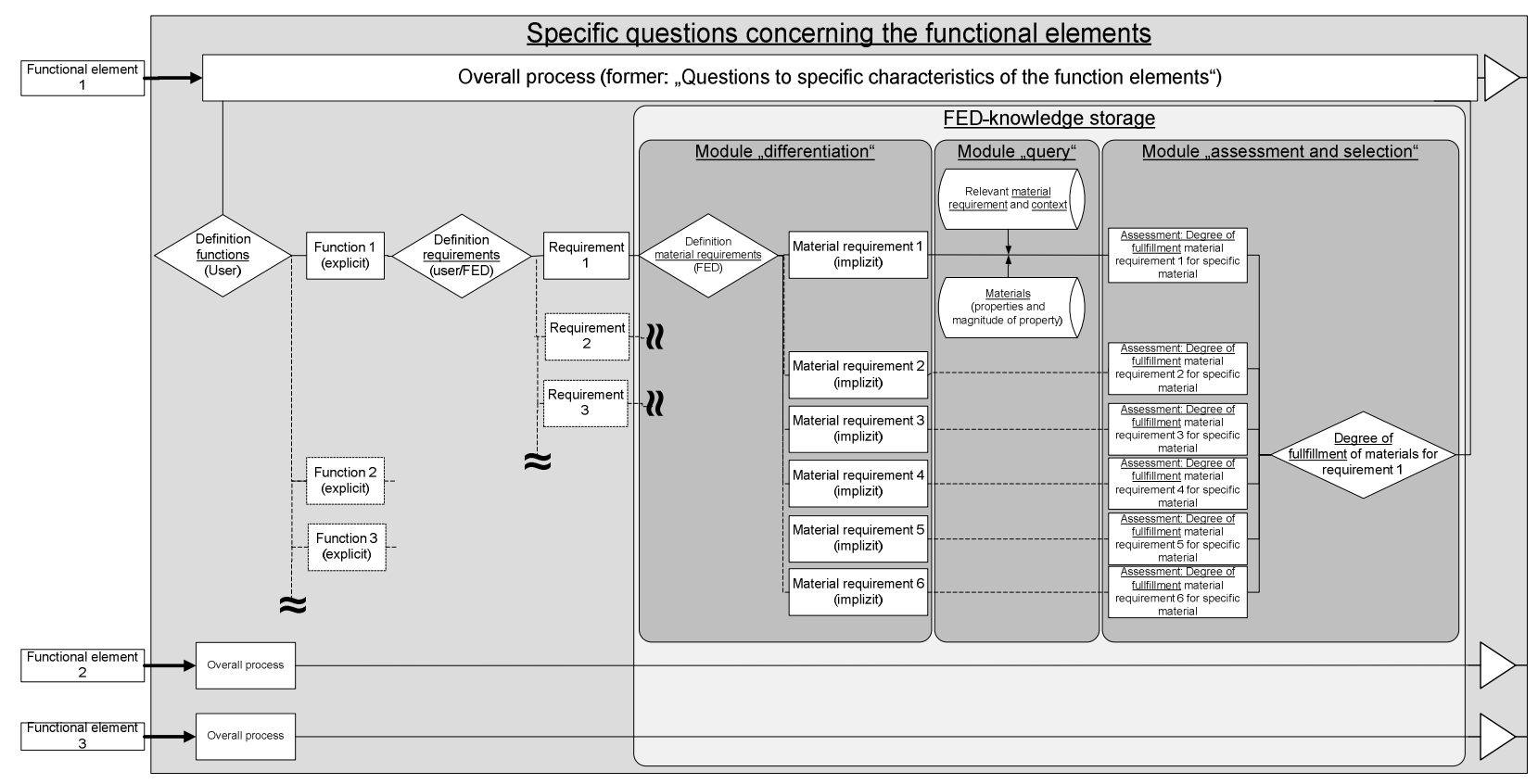

Fig. 8: Schematic diagram of the material selection process based on functional elements

The described multidimensional material selection process includes all of the materials that are available in a database. Due to the identification of material solutions based on individual functional elements with a maximum matching degree of the requirements and properties profiles, the number of potential material solutions is limited in a first step to three to ten different materials in the upper assessment range. In the case of a restriction because of the definition of generic or interstitial requirements, material solutions of subsequent assessment ranks will also be taken into consideration. As far as the material selection being based on a local functional element is concerned, individual materials or material groups are not excluded at any time, except in the case of a restriction. As a result, the solution set of potential materials is never "empty" during this "soft assessment process", and not in the case of a restriction.

The use of materials with locally modified properties and, thereby, so-called material innovations are supported, insofar as due to the various thermo-mechanical treatments, materials with locally modified properties have a higher degree of fulfillment of material requirements and, thereby, also of their design requirements than those materials in their original state, i.e. parent materials. Especially in the case of contrary requirements that are to be fulfilled by the functional elements, materials with locally optimized properties come to the fore as a result of the described assessment process. A classification within a material database on which the material selection process is founded must be based on the initial state ("parent material") and on the variation thereof, which can be obtained by a thermo-mechanical treatment ("derivative"). In order to promote the use of a small number of parent materials with local properties that are adapted with the aid of requirementspecific thermo-mechanical processes (e.g. in view of directly adjacent functional elements), a classification into material groups or material families must be performed.

The described method, for the identification of a selection of target-oriented materials, based on a local functional element with the consideration of accompanying conditions with the definition of interfaces and global boundary conditions, thereby meets the requirements of a top-down approach as described, for example, in [6], transfers it into a local view of the component, and does not include the already described crucial disadvantage of a graphical solution-finding process according to [11]. The described selection process leads to a group of potential material solutions for a local functional element, while considering the generic and interstitial requirements, and enables a mutual comparison as well as a comparison with a fictitious material-based ideal solution. This group of solutions is the result of a search that quickly reduces the large number of existing engineering 
materials to those materials that are suitable for the specific application, based on properties and their quantitative and qualitative description. The final number of materials on the resulting list strongly depends on the capability of the user in procuring the required data and on the weightings performed by the user. Access to continuously updated and consistent databases clearly offers the highest potential.

Individual functional elements, however, can only be described to a limited extent based on their specific requirements. If the level of detailing of a functional element increases, only a limited number of different questions can be formulated in order to put the material selection process into concrete terms. It is only possible to further reduce the number of potential materials if the associated interfaces of the functional elements are also taken into consideration.

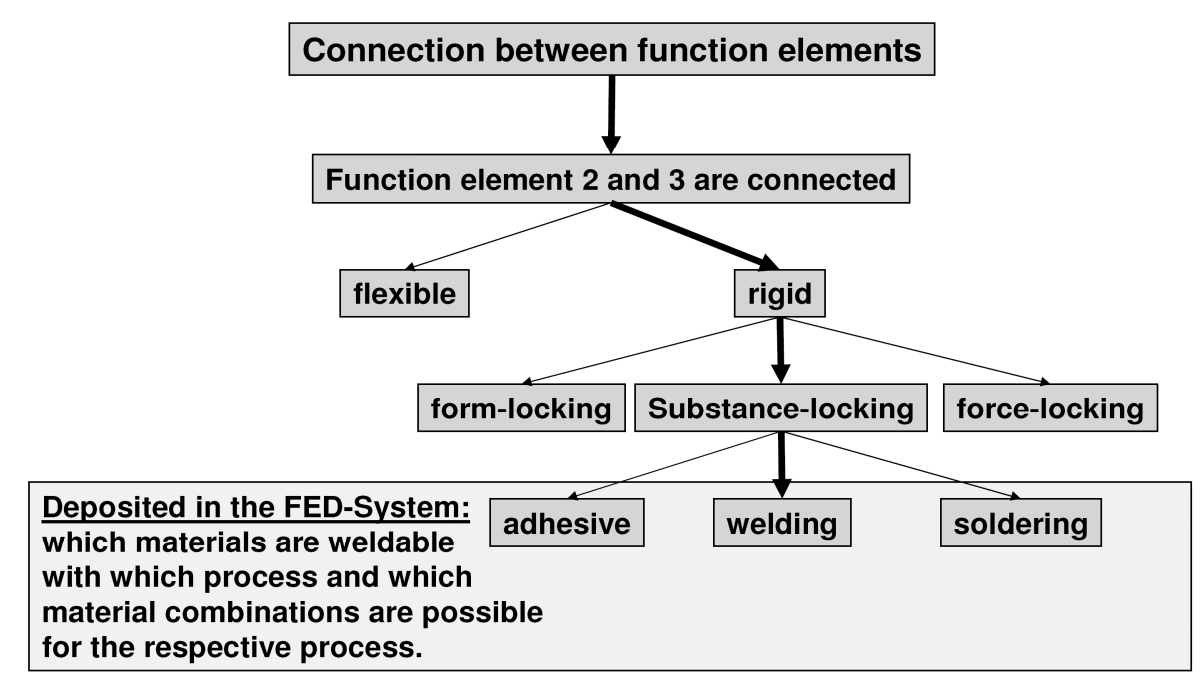

Fig. 9: Interface definition of the functional elements 2 and 3 (also see Fig. 4)

Targeted questions enable the definition of the connection between the functional elements via the interfaces. According to Fig. 4, for example, the functional elements 2 and 3 are connected through the material-joining process of welding. The basis of the suitability of the material-based joining of functional elements is the material requirement weldability. In the course of the material selection process, the weldability is represented by the welding suitability criterion. This term basically covers the reactions of the parent material to the welding process. Since during welding the material is subject to an unwanted heat treatment, changes in the mechanical-technological properties of the parent material cannot be avoided. These changes in material properties are mainly caused by structural changes, which may lead to embrittlement, decreased corrosion resistance, or increased stress in the component. If a material is suitable for welding, this means that its mechanicaltechnological characteristics are only slightly, and to a tolerable extent, affected by the welding process. The welding suitability of the parent material can be further differentiated into the subterms of chemical composition, metallurgical properties, and physical properties.

As a consequence, the definition of an interface by means of a material-joining process within the systematic FED design approach (compare Fig. 3) represents a restriction in the material selection process for the individual functional elements.

In addition, joining by welding leads to additional characteristic changes of a metallurgical (structure, grain size), physical (hardness, stress-strain relations, and notched bar impact work), and chemical nature in the joining zone, which depend on the welding process that is applied. In this context, the systematic FED design approach provides information as to which characteristic properties can be achieved via which processes and process parameters. The basis for the provision of these fundamental data is the identification and representation of local material properties in the joining zone of selected welded joints. 


\section{Generation and Characterization of Local Material Properties}

Material selection and weldability. Ungalvanized thin sheets made of conventional deepdrawing and higher-strength steels were used for studying and producing dissimilar material joints. The plate material that was used had a thickness of between $1.0 \mathrm{~mm}$ and $1.5 \mathrm{~mm}$. The parent material properties are shown in Table 1. The welding of these steels is rather unproblematic. A G4Sil (1.5130) wire with a diameter of $1.2 \mathrm{~mm}$ was used as the filler material.

Table 1: The parent materials that were used

\begin{tabular}{|c|c|c|c|c|}
\hline Material & $\begin{array}{c}\text { Sheet } \\
\text { thickness } \\
{[\mathrm{mm}]}\end{array}$ & $\begin{array}{c}\text { Yield strength } \\
{\left[\mathrm{N} / \mathrm{mm}^{2}\right]}\end{array}$ & $\begin{array}{c}\text { Tensile strength } \\
{\left[\mathrm{N} / \mathrm{mm}^{2}\right]}\end{array}$ & $\begin{array}{c}\text { Elongation at } \\
\text { break [\%] }\end{array}$ \\
\hline DC steels & 1.5 & 150 & 275 & 44 \\
\hline DC 04 (1.0338) & 1.0 & 134 & 267 & 43.6 \\
\hline DC 05 (1.0312) & & & 669 & 24.8 \\
\hline Dual-phase (DP) steels & 1.0 and 1.5 & 349 & & \\
\hline DP 600 (1.0936) & 1.0 & 280 & 629 & 43.6 \\
\hline Austenitic Cr-Ni steel & & & & \\
\hline 1.4301 & & &
\end{tabular}

For the creation of a firm joint of dissimilar materials, i.e. of unalloyed or low-alloy steel and $\mathrm{Cr}-\mathrm{Ni}$ steel, certain boundary conditions must be taken into consideration. The welding of these black-andwhite-joints in turn leads to the formation of new structures with unfavorable properties, which is due to the melting of the filler material and the fusion and mixing of the parent materials. This is why a suitable filler material is selected with the aid of the Schaeffler diagram, based on the chemical composition of the parent and filler materials via the determination of the chromium and nickel equivalents.

Based on a dilution rate of approximately $25 \%$, the use of the filler material (FM) 1.4576 in turn results in an austenite-ferrite structure with a delta-ferrite-content of approximately $5 \%$ in the weld deposit.

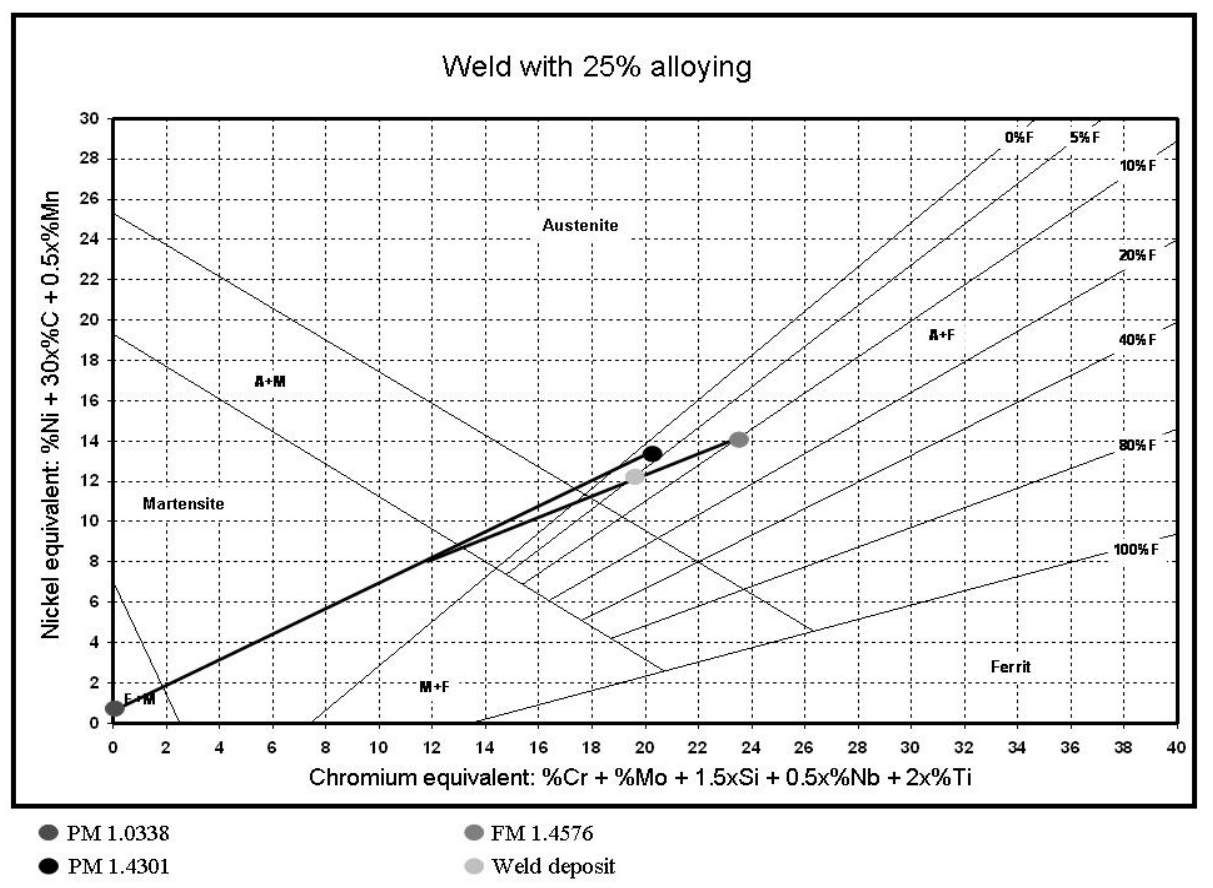

Fig. 10: Schaeffler diagram for the selection of the filler material 
Test equipment and performance of the welding tests. The Fronius TransPlus Synergic 4000CMT, which was used for the experiment, is a digital, microprocessor-controlled inverter welding power source. It is used for MIG and MAG welding. The technical data of the system are shown in Table 2.

Table 2: Technical data of the GMA welding system

\begin{tabular}{|l|l|}
\hline Line voltage & $3 \times 400 \mathrm{~V}$ \\
\hline Line frequency & $50 / 60 \mathrm{~Hz}$ \\
\hline Primary continuous power & $12.2 \mathrm{kVA}$ \\
\hline Efficiency cos $(\varphi)$ & 0.99 \\
\hline Welding current range MIG/MAG & $3-400 \mathrm{~A}$ \\
\hline Operating voltage MIG/MAG & $14.2-34.0 \mathrm{~V}$ \\
\hline
\end{tabular}

The high-frequency welding system that is used at the Institute of Welding and Machining is a prototype that was made by KUKA Schweißanlagen GmbH, Augsburg (Germany). It can be used for inductive as well as conductive energy transmission. The specific system data can be found in Table 3.

Table 3: Technical data of the high-frequency welding system

\begin{tabular}{|l|l|}
\hline Nominal operating frequency & $360 \mathrm{kHz} \pm 20 \%$ \\
\hline Nominal power at $100 \%$ & $85 \mathrm{~kW}$ \\
\hline Connected load & $\approx 160 \mathrm{kVa}$ \\
\hline Operating voltage & $400 \mathrm{~V} / 50 \mathrm{~Hz}$ \\
\hline Upsetting force & $40 \mathrm{kN} \mathrm{max.}$ \\
\hline Control voltage & $24 \mathrm{~V}$ \\
\hline
\end{tabular}

Plates with the dimensions of $145 \times 150 \times 1$ (or 1.5) $\mathrm{mm}$ are used for the high-frequency welding process. The projection length a (i.e. the length at which the plates project from the current contact rail) and the joint clearance $b$ (i.e. the clearance between the joint edges) are set at the welding machine, and the plates are chucked with a chucking tool. The joint edges are heated when the highfrequency alternating current is switched on. The heated joint edges are pressed together with a defined upsetting force or with a compressive stress that refers to the surface of the joint edges. As a result, the materials are materially joined. The compressive stress must be sufficiently high in order to ensure a material joint, while at the same time the edge offset or buckling of the plates must be avoided. 
Performance of the welding tests. The welding process conditions for various material combinations were determined in preliminary tests and used for producing the welds to be tested (see Tables 4 and 5).

Table 4: GMA welding process conditions

\begin{tabular}{|c|c|c|c|c|c|c|c|}
\hline $\begin{array}{c}\text { Parameter } \\
\text { set }\end{array}$ & Material & $\begin{array}{c}\text { Sheet } \\
\text { thickness } \\
\text { in mm }\end{array}$ & $\begin{array}{c}\text { Clearance } \\
\text { in mm }\end{array}$ & $\begin{array}{c}\text { Current } \\
\text { in A }\end{array}$ & $\begin{array}{c}\text { Voltage } \\
\text { in V }\end{array}$ & $\begin{array}{c}\text { Wire } \\
\text { feed rate } \\
\text { in m/min }\end{array}$ & $\begin{array}{c}\text { Welding } \\
\text { speed in } \\
\text { m/min }\end{array}$ \\
\hline 1 & $\begin{array}{c}1.0338 \\
- \\
1.4301\end{array}$ & $1.5 / 1.0$ & 0.6 & 119 & 13.8 & 2.9 & 0.73 \\
\hline 2 & $\begin{array}{c}1.0338 \\
- \\
1.0936\end{array}$ & $1.5 / 1.0$ & 0.5 & 110 & 16 & 2.5 & 0.93 \\
\hline 3 & $\begin{array}{c}1.0338 \\
- \\
1.0936\end{array}$ & $1.5 / 1.0$ & 0.5 & 110 & 16 & 2.2 & 0.93 \\
\hline 4 & $\begin{array}{c}1.0312 \\
-\end{array}$ & $1.0 / 1.0$ & 0.5 & 87 & 15 & 1.6 & 0.93 \\
\hline
\end{tabular}

Table 5: HF welding process conditions

\begin{tabular}{|c|c|c|c|c|c|}
\hline $\begin{array}{c}\text { Parameter } \\
\text { set }\end{array}$ & Material & $\begin{array}{c}\text { Sheet thickness } \\
\text { in mm }\end{array}$ & $\begin{array}{c}\text { Clearance } \\
\text { in } \mathrm{mm}\end{array}$ & $\begin{array}{c}\text { Projection } \\
\text { length in } \mathrm{mm}\end{array}$ & $\begin{array}{c}\text { Upsetting } \\
\text { force in N }\end{array}$ \\
\hline 5 & $1.0338-1.0936$ & $1.5 / 1.0$ & 2 & $5.0 / 5.0$ & 10018 \\
\hline 6 & $1.0338-1.0338$ & $1.5 / 1.5$ & 2 & $5.0 / 5.0$ & 10002 \\
\hline
\end{tabular}

Characterization of local material properties. In a first step, the analysis of the selected welded joints of dissimilar materials enables the exemplary representation of locally resolved material properties. This requires a well-mastered welding process with describable process conditions and, thereby, a known characteristic profile. The characteristic profile of the weld seam is divided into several zones with certain characteristic properties (see Fig. 11).

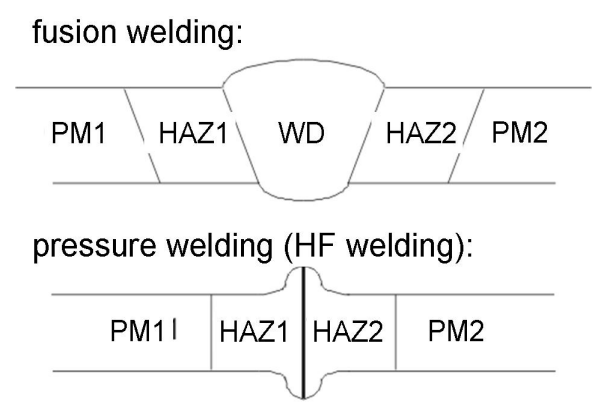

Fig. 11: Schematic representation of the multi-zone model

These zones are the parent material zones 1 and 2, heat-affected zones 1 and 2, and weld deposit or joining zone. For these local areas, certain metallurgical, physical, chemical, and technological (formability, machinability, and weldability) properties can be stated directly and indirectly. Metallurgical material properties are the structure, grain size, etc. The physical material properties 
are described by the hardness, notched impact strength, modulus of elasticity, strain and fracture behavior, etc. The chemical composition, dilution ratio, and corrosion resistance, for example, are part of the chemical properties.

The following sections describe the test results of the selected welds and their respective properties. Apart from the global behavior of the weld seam, e.g. during a tensile test, certain locally resolved material properties, such as the hardness distribution, structure, and strain behavior, are represented with the aid of the laser-optical strain measurement.

Tensile test. The characteristic tensile test values are determined with the aid of a Zwick-Roell Z-100 universal materials testing machine. The maximum load of the machine is $100 \mathrm{kN}$. The flatbar tensile test specimens that were made of the welded plates were stretched in the testing machine until breakage occurred. The shape of the flat-bar tensile test specimens is shown in Fig. 12. The weld seam was across the direction of pull.

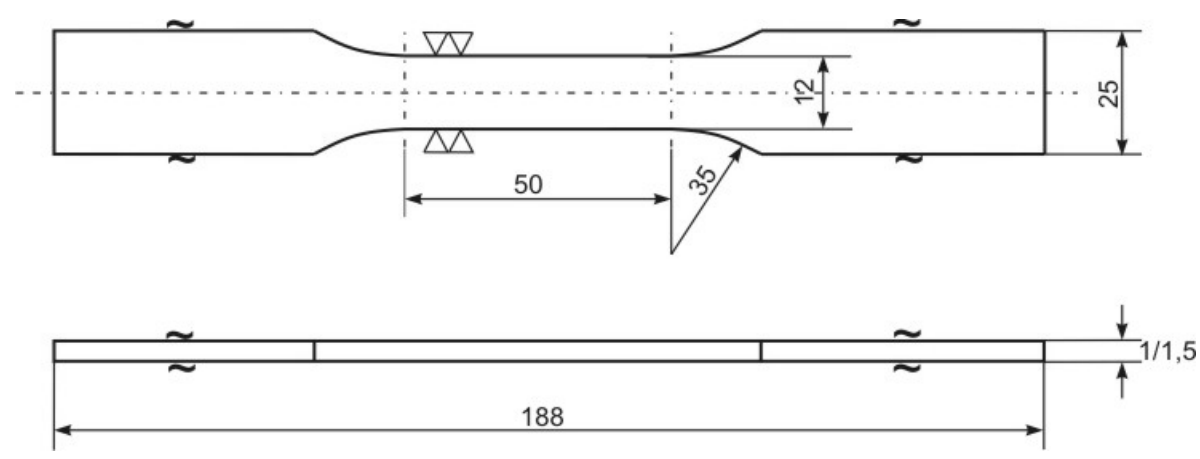

Fig. 12: Unnotched flat-bar tensile test specimen for fusion-welded butt welds

Due to the small sheet thickness of the flat-bar specimens of $1 \mathrm{~mm}$ or $1.5 \mathrm{~mm}$, respectively, it is not possible to test the individual weld zones (HAZ, WD) directly via a tensile test. Instead, laseroptical strain measurements via ESPI were performed on selected specimens.

Table 6: Selected material and thickness combinations as well as the corresponding tensile strength characteristics referring to the sheet thickness

\begin{tabular}{|c|c|c|c|c|c|}
\hline Parameter set & Material & $\begin{array}{c}\text { Yield } \\
\text { strength in } \\
\mathrm{N} / \mathrm{mm}^{2}\end{array}$ & $\begin{array}{c}\text { Tensile } \\
\text { strength in } \\
\mathrm{N} / \mathrm{mm}^{2}\end{array}$ & $\begin{array}{c}\text { Elongation at } \\
\text { break in \% }\end{array}$ & $\begin{array}{c}\text { Incipient } \\
\text { fracture } \\
\text { location }\end{array}$ \\
\hline 1 & $\begin{array}{c}1.0338-1.4301 \\
1.5 / 1.0\end{array}$ & $173 / 259$ & $305 / 457$ & 24.4 & GW 1.0338 \\
\hline 2 & $\begin{array}{c}1.0338-1.0936 \\
1.5 / 1.0\end{array}$ & $176 / 264$ & $301 / 451$ & 24.7 & GW 1.0338 \\
\hline 3 & $\begin{array}{c}1.0338-1.0936 \\
1.5 / 1.0\end{array}$ & $174 / 261$ & $298 / 448$ & 25 & GW 1.0338 \\
\hline 4 & $\begin{array}{c}1.0312-1.0936 \\
1.0 / 1.0\end{array}$ & 170 & 295 & 21.8 & GW 1.0312 \\
\hline 5 & $\begin{array}{c}1.0338-1.0936 \\
1.5 / 1.0\end{array}$ & $182 / 273$ & $298 / 447$ & 22 & GW 1.0338 \\
\hline
\end{tabular}

The tensile tests were performed in a displacement-controlled manner. In all of the cases, the tensile tests led to a ductile fracture in the unaffected parent material.

Hardness testing. For process-related reasons, the hardness of the weld seam zones (heataffected zone and weld deposit) often differs from the hardness of the parent materials. The strain and strength values with strong variations may lead to unwanted properties of the welded joint. For the present evaluations, the hardness distribution across the weld seam from parent material 1 via 
the heat-affected zones (HAZ) and the weld deposit up to parent material 2 was measured. In order to determine the low-load hardness values, a type M SHIMADZU MICRO HARDNESS tester was used. In accordance with DIN 50133, the Vickers hardness HV0.2 was determined with an applied load of $1.96 \mathrm{~N}$, which corresponds to a load of $0.2 \mathrm{~kg}$. The loading time per hardness indentation was $15 \mathrm{~s}$ at intervals of $0.25 \mathrm{~mm}$ between the individual hardness indentations. The following sections describe the hardness distributions of the selected welded joints.

Dissimilar joint of $\mathbf{1 . 0 3 3 8}$ and 1.4301. Based on the hardness of the 1.0338 parent material of 95 HV0.2, the hardness values increase in the heat-affected zone (HAZ). The weld deposit shows slightly higher hardness values than the 1.4301 parent material (see Fig. 13)

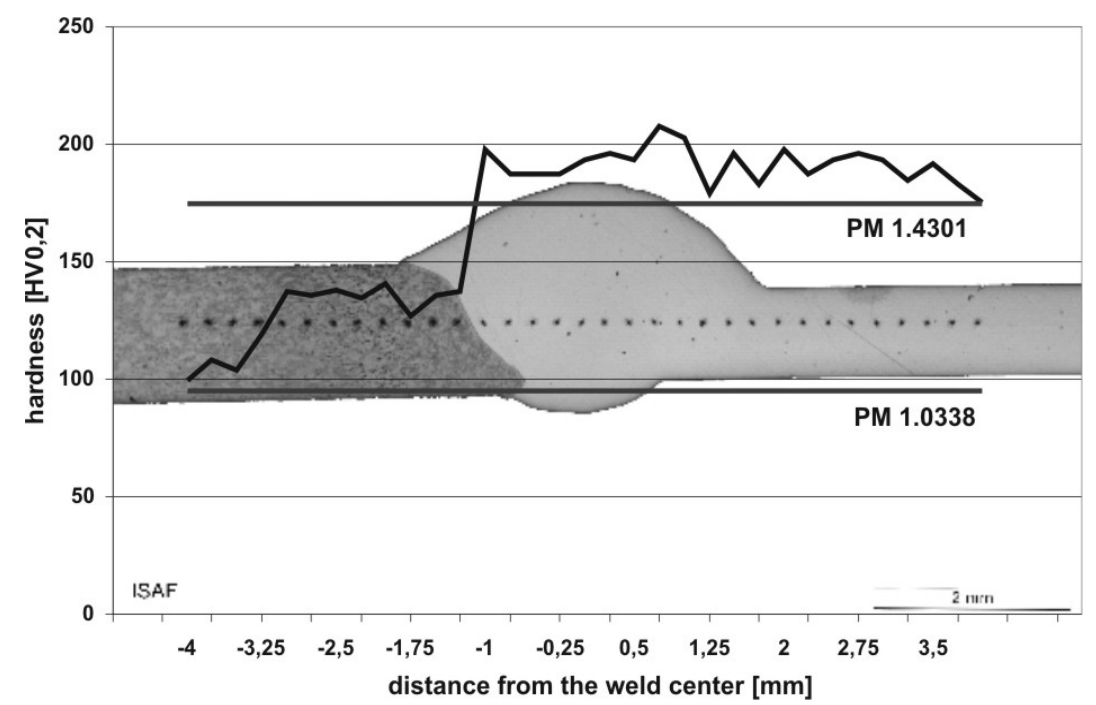

Fig. 13: Hardness distribution of the dissimilar joint of 1.0338 and 1.4301 (parameter set 1)

Dissimilar joint of 1.0338 and 1.0936.

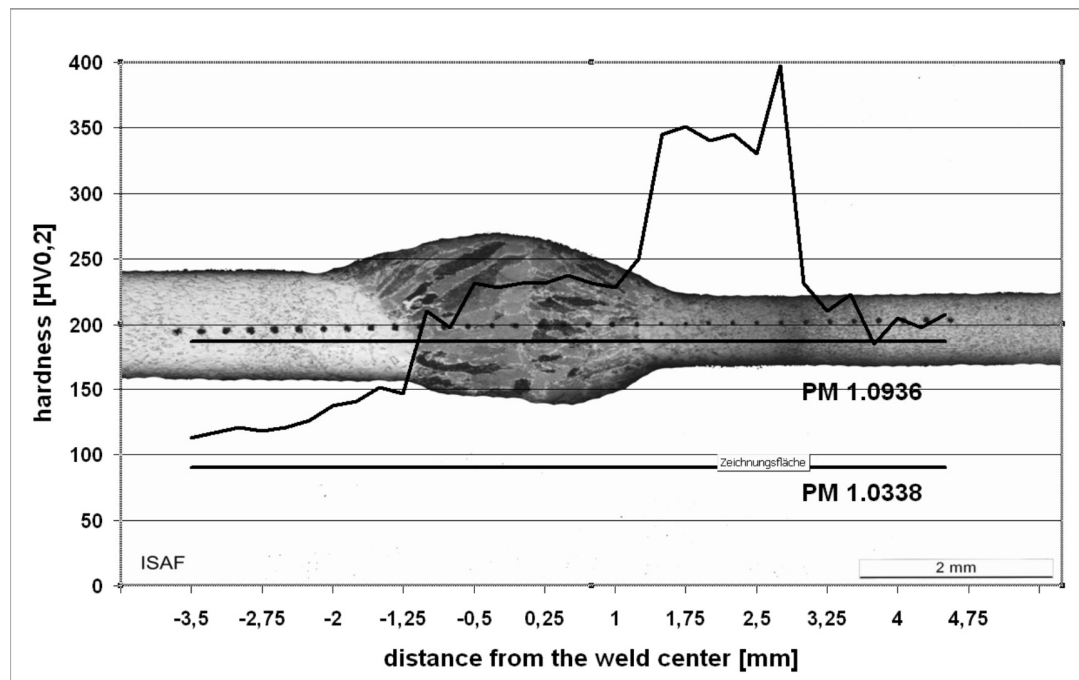

Fig. 14: Hardness distribution of the dissimilar joint of 1.0338 and 1.0936 (parameter set 2)

A characteristic feature of the 1.0338-1.0936 material combination is the hardness maximum in the heat-affected zone of the 1.0936 material, as shown in Fig. 14 and 15. The weld deposit 1.5130 reaches similar hardness values as the parent material 1.0936. When the distance to the weld seam increases, the hardness profile of the 1.0338 material decreases until it reaches that of the parent material. 


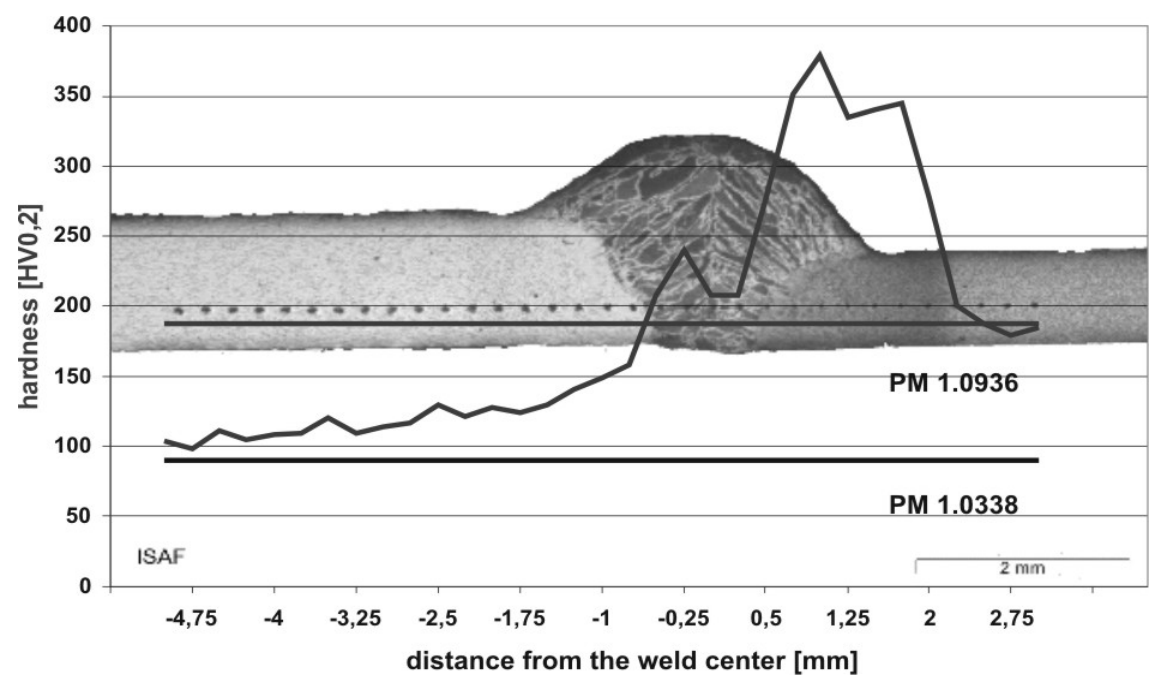

Fig. 15: Hardness distribution of the dissimilar joint of 1.0338 and 1.0936 (parameter set 3)

Dissimilar joint of $\mathbf{1 . 0 3 1 2}$ and 1.0936. Similar to the 1.0338 material, the hardness of 1.0312 increases towards the weld deposit. The weld deposit reaches hardness values that correspond to those of parameter sets 2 and 3. The hardness maximum of the abovementioned 1.0936 material can also be seen here.

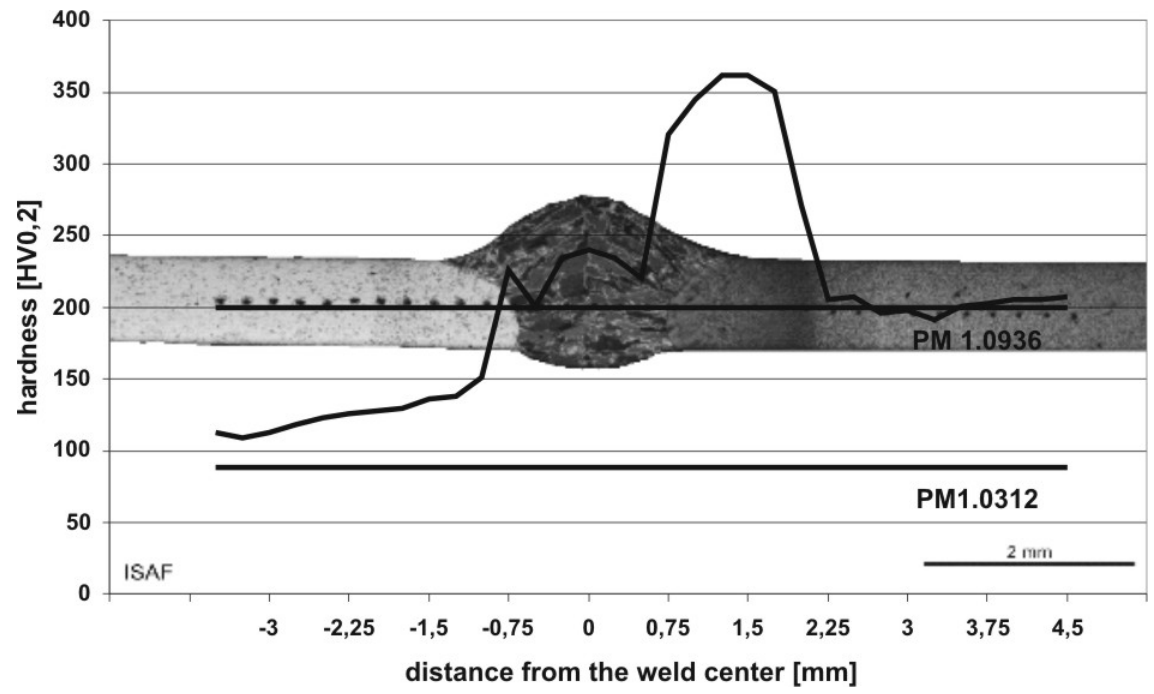

Fig. 16: Hardness distribution of the dissimilar joint of 1.0312 and 1.0936 (parameter set 4) 
Dissimilar joint of 1.0338 and 1.0936 HF. Similar to the GMA-welded specimens, the highfrequency-welded dissimilar joints of 1.0338 and 1.0936 also show the already mentioned hardness maximum in the heat-affected zone of the 1.0936 material.

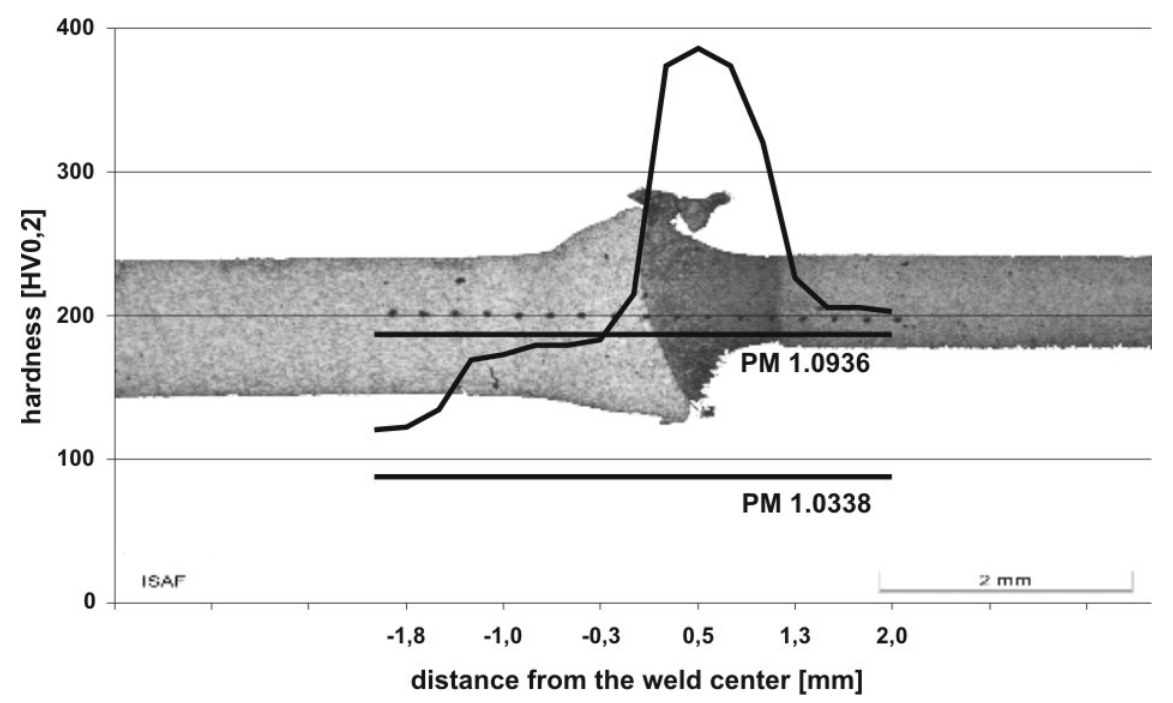

Fig. 17: Hardness distribution of the dissimilar joint of 1.0338 and 1.0936 (parameter set 5)

Weld of 1.0338 and $1.0338 \mathrm{HF}$. Based on the parent material hardness of the 1.0338 material, the hardness values increase towards the middle of the weld seam and reach approximately 138 HV0.2.

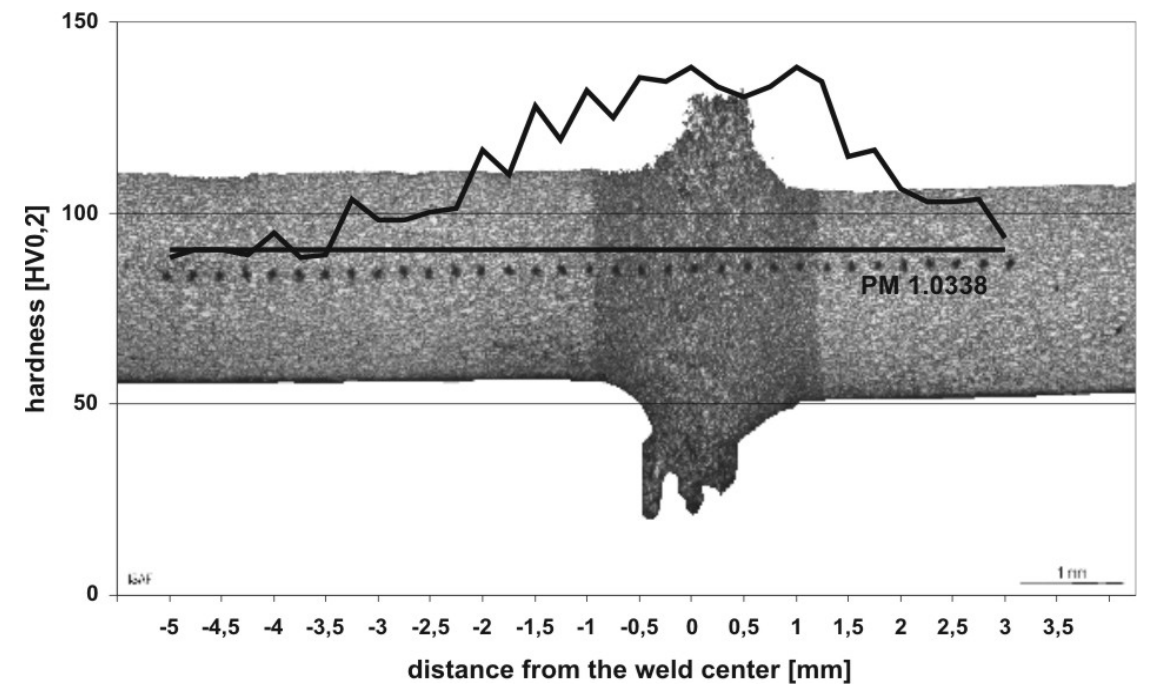

Fig. 18: Hardness distribution of the weld of 1.0338 and 1.0338 (parameter set 6) 
Table 7: Summary of the measured hardness values

\begin{tabular}{|c|c|c|c|c|c|c|}
\hline $\begin{array}{c}\text { Parameter } \\
\text { set }\end{array}$ & Material & PM 1 & HAZ 1 & $\begin{array}{c}\text { WD/joining } \\
\text { zone }\end{array}$ & HAZ 2 & PM 2 \\
\hline 1 & $\begin{array}{c}1.0338- \\
1.4301\end{array}$ & 95 & $95-141$ & $187-208$ & $179-196$ & 175 \\
\hline 2 & $\begin{array}{c}1.0338- \\
1.0936\end{array}$ & 95 & $95-151$ & $197-250$ & $330-398$ & 187 \\
\hline 3 & $\begin{array}{c}1.0338- \\
1.0936\end{array}$ & 95 & $95-157$ & $207-240$ & $273-344$ & 187 \\
\hline 4 & $\begin{array}{c}1.0312- \\
1.0936\end{array}$ & 90 & $90-151$ & $200-234$ & $270-362$ & 187 \\
\hline 5 & $\begin{array}{c}1.0338- \\
1.0936\end{array}$ & 95 & $95-180$ & - & $320-385$ & 187 \\
\hline 6 & $1.0338-$ & 95 & $95-138$ & - & $138-95$ & 95 \\
\hline
\end{tabular}

Structural analysis. Based on the light-microscopy analysis performed, the structural components of the welded joint and of the parent materials are assigned to the 5-zone-model (parent materials 1 and 2, heat-affected zones 1 and 2, and the weld deposit or joining zone) as additional material properties (compare Fig. 5). As a general overview, Fig. 19 shows the structure of the parent materials.

The parent materials 1.0338 and 1.0312 are characterized by a ferritic structure. A specific feature of the dual-phase steel 1.0936 is its ferritic structure with insular martensite. 1.4301 has an austenitic structure with twin boundaries.

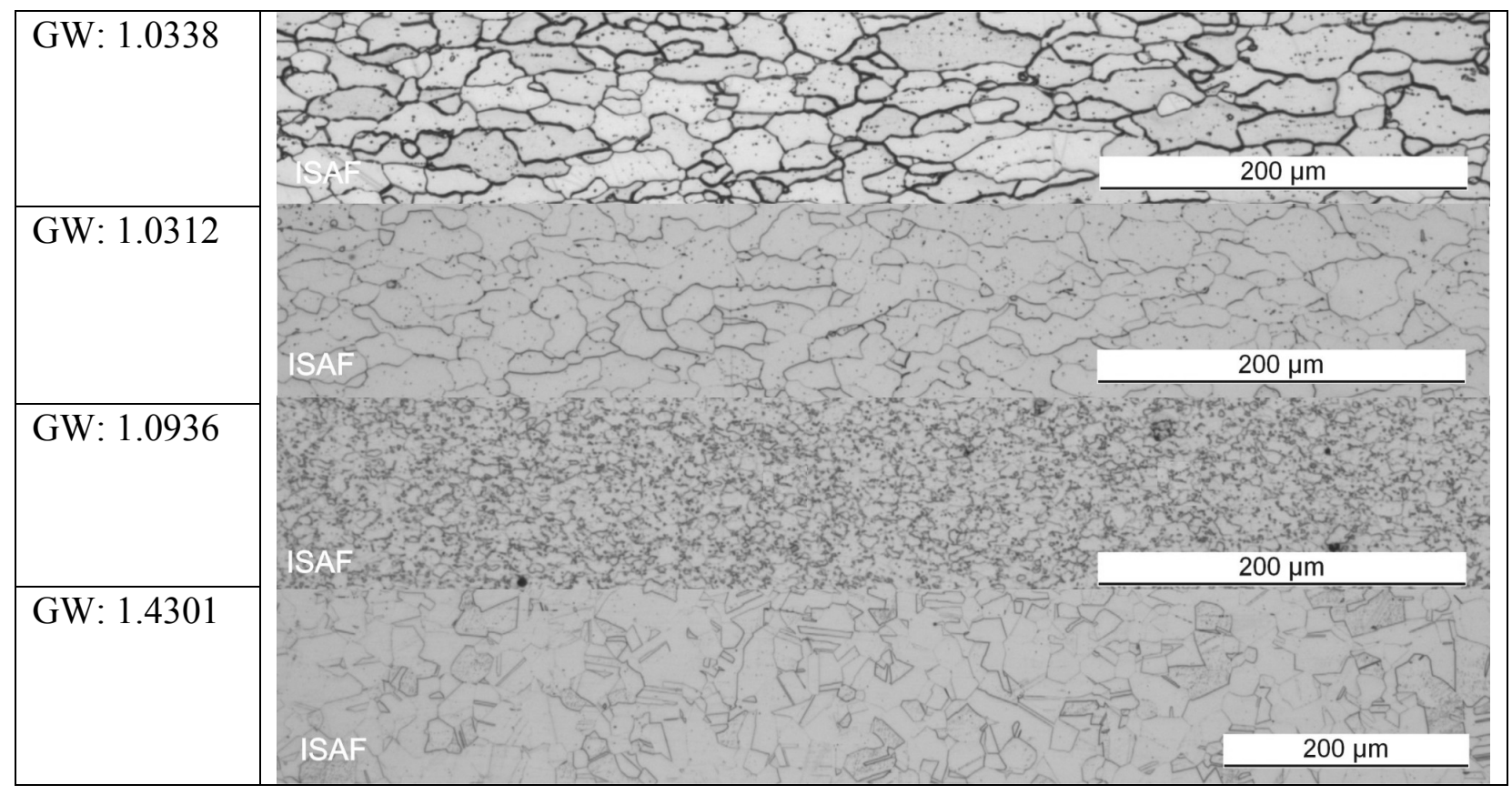

Fig. 19: Parent material structures 
Dissimilar joint of 1.0338 and 1.4301. The heat-affected zone of the 1.0338 material shows a transition from fine-grained ferrite to a coarse ferritic structure towards the weld seam. The weld deposit has an austenitic cast structure. The transition from the weld deposit to the 1.4301 material is characterized by a pasty fusion line with an austenitic solidification structure. There is no distinct fine- or coarse-grained zone. The solidification structure is followed by the 1.4301 parent material with its austenitic structure.
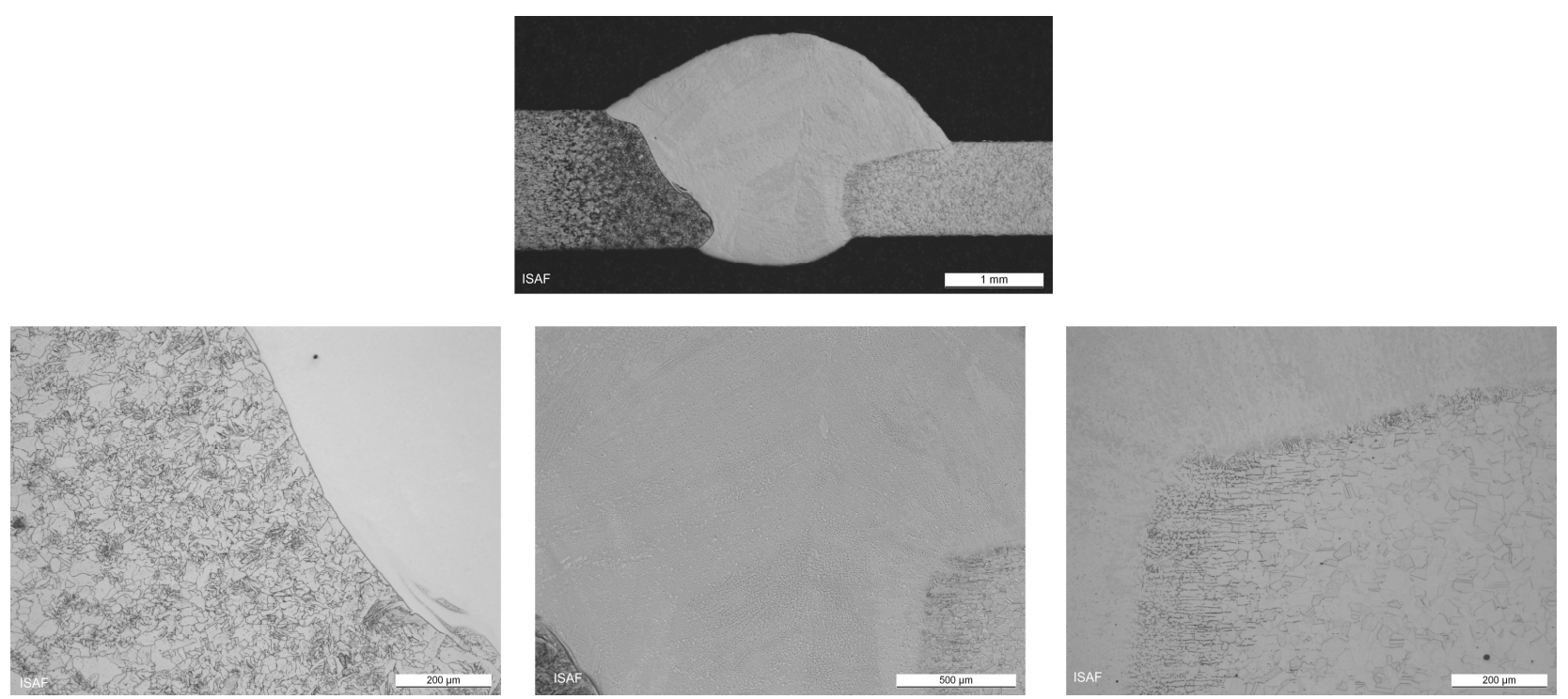

Fig. 20: Structure of a MIG-welded joint of 1.0338 and 1.4301 (parameter set 1)

Dissimilar joints 1.0338-1.0936 and 1.0312-1.0936. Because of their approximately similar structures, the parameter sets 2,3 , and 4 will be summarized.

The heat-affected zone 1 of the 1.0338 or 1.0312 material shows a ferritic fine-grained structure that turns into a coarse-grained zone towards the weld seam. The pearlitic cast structure is typical of the weld deposit of 1.5130. Similar to the heat-affected zone 1 of the 1.0338 or 1.0312 material, a coarse-grained structure adjoins the weld deposit in the area of the heat-affected zone 2 of the 1.0936 material. This coarse-grained structure gradually turns into a fine-grained structure when the distance increases. In this case, the structural constituents are martensitic with parts of bainite. Due to the lower energy input in parameter set 3, the weld deposit is thinner than in parameter set 2.
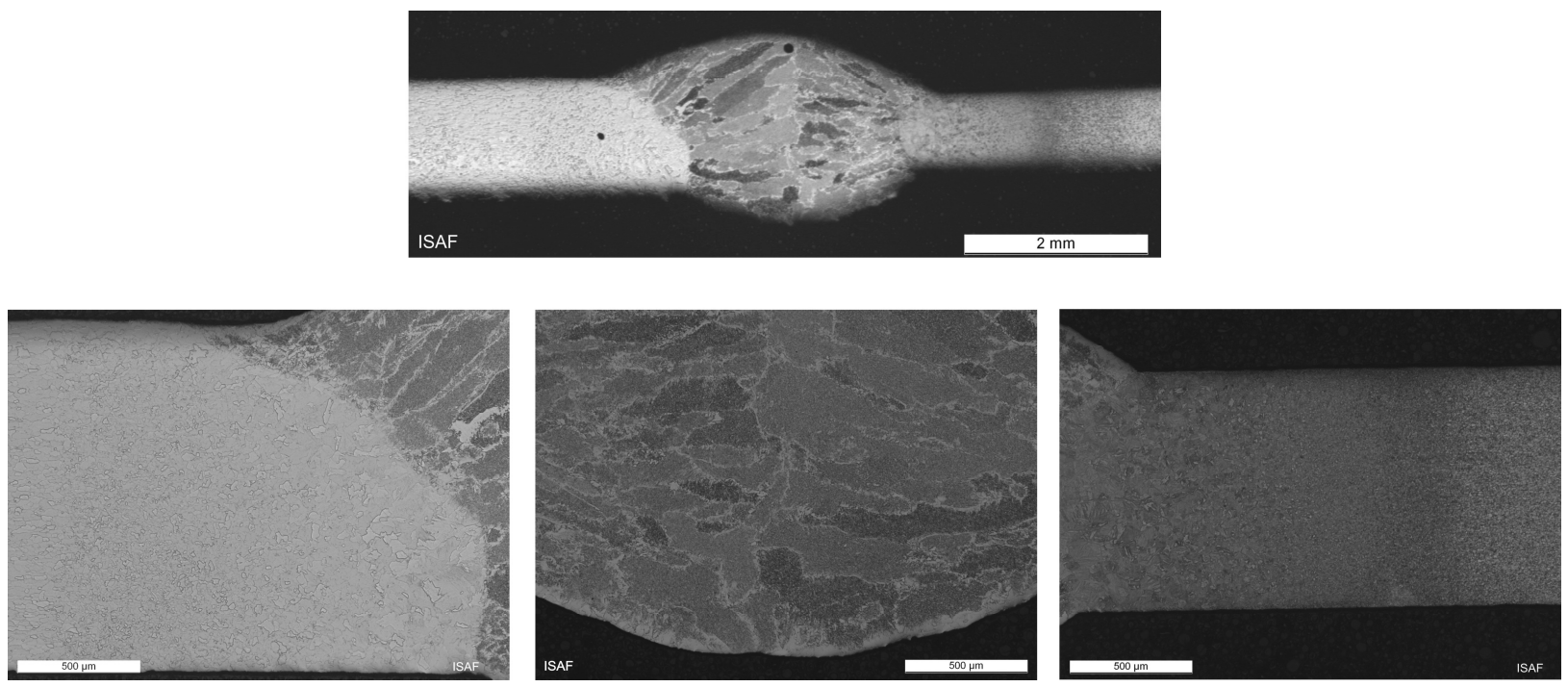

Fig. 21: Structure of a MAG-welded joint of 1.0338 and 1.0936 (parameter set 2) 

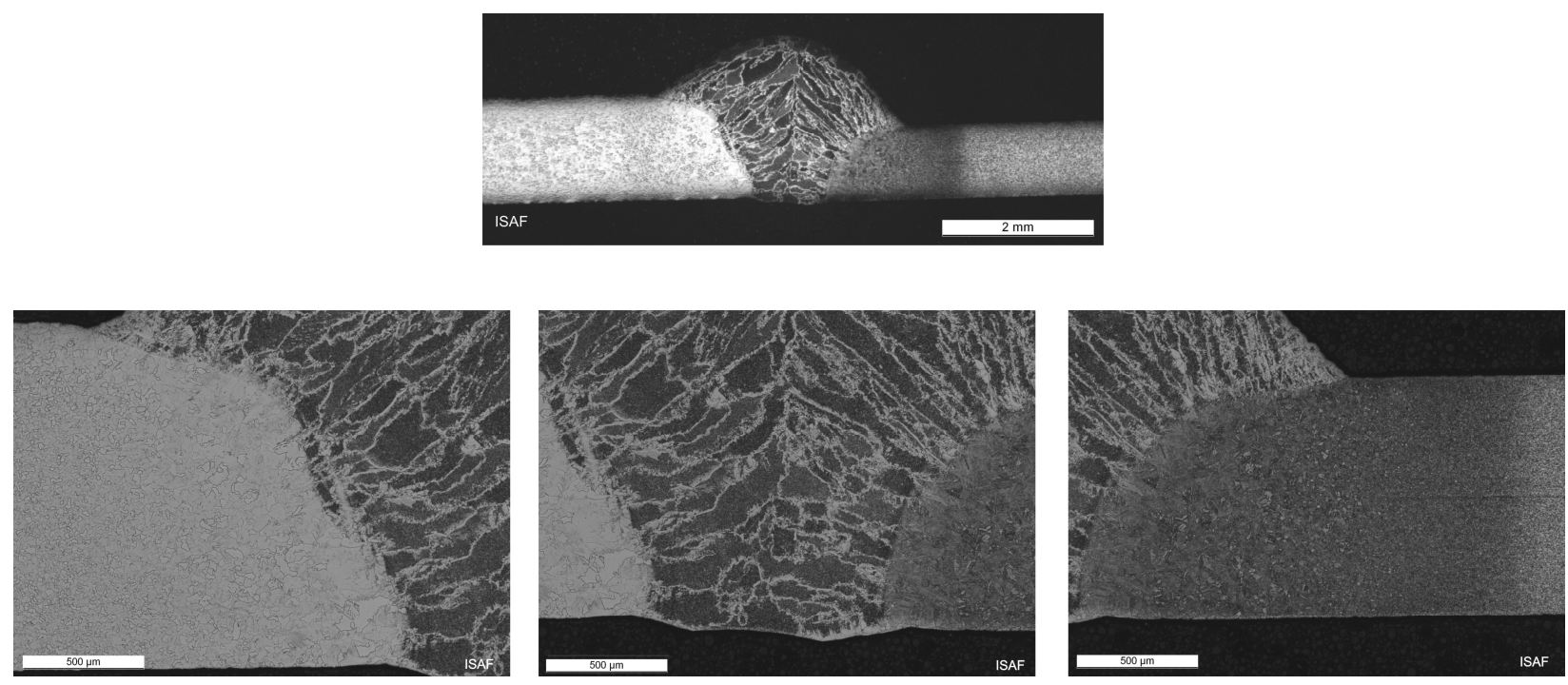

Fig. 22: Structure of a MAG-welded joint of 1.0338 and 1.0936 (parameter set 3)
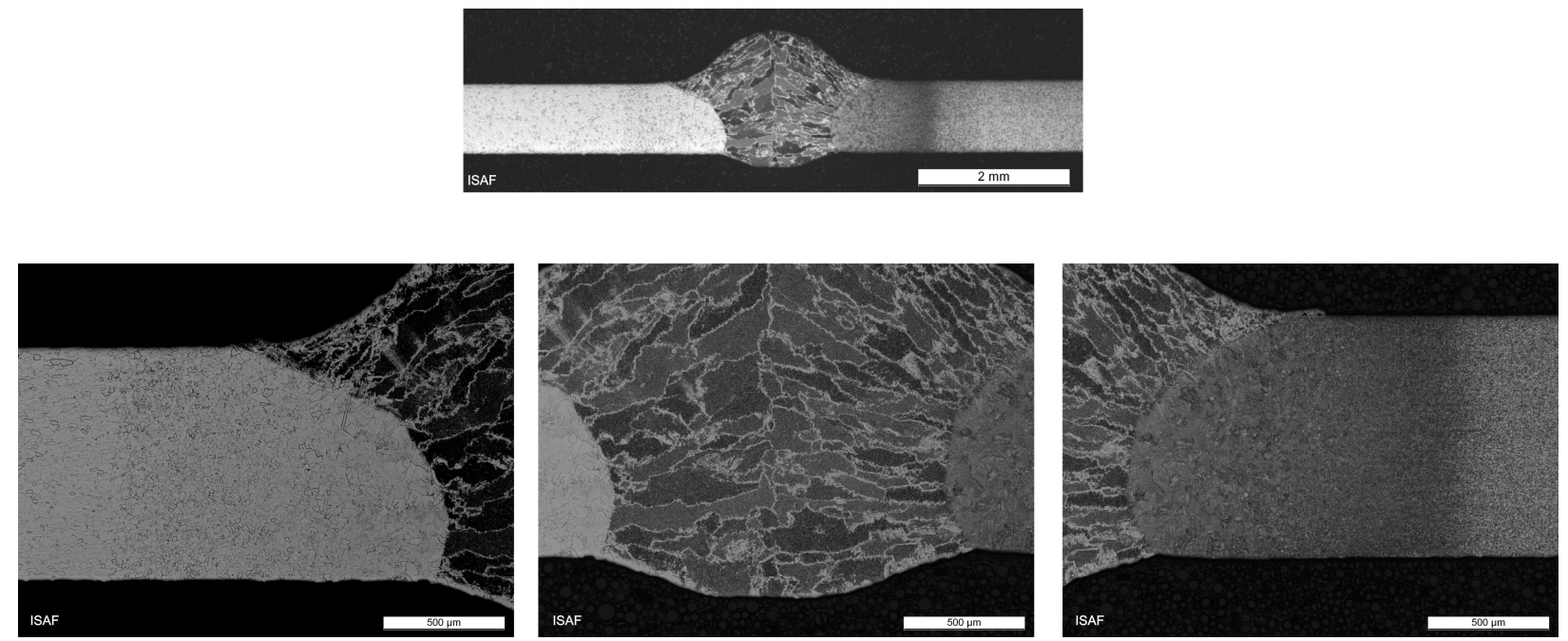

Fig. 23: Structure of a MAG-welded joint of 1.0312 and 1.0936 (parameter set 4) 
Dissimilar joints 1.0338-1.0936 and 1.0312-1.0936. Following the 1.0338 parent material, the heat-affected zone is characterized by a fine-grained ferritic structure that turns into a coarse-grained ferrite structure. The fusion line between the materials 1.0338 and 1.0936 is clearly visible. In the area of the heat-affected zone 2 of the 1.0936 material, a coarse-grained martensitic structure appears and becomes increasingly finer towards the parent material.
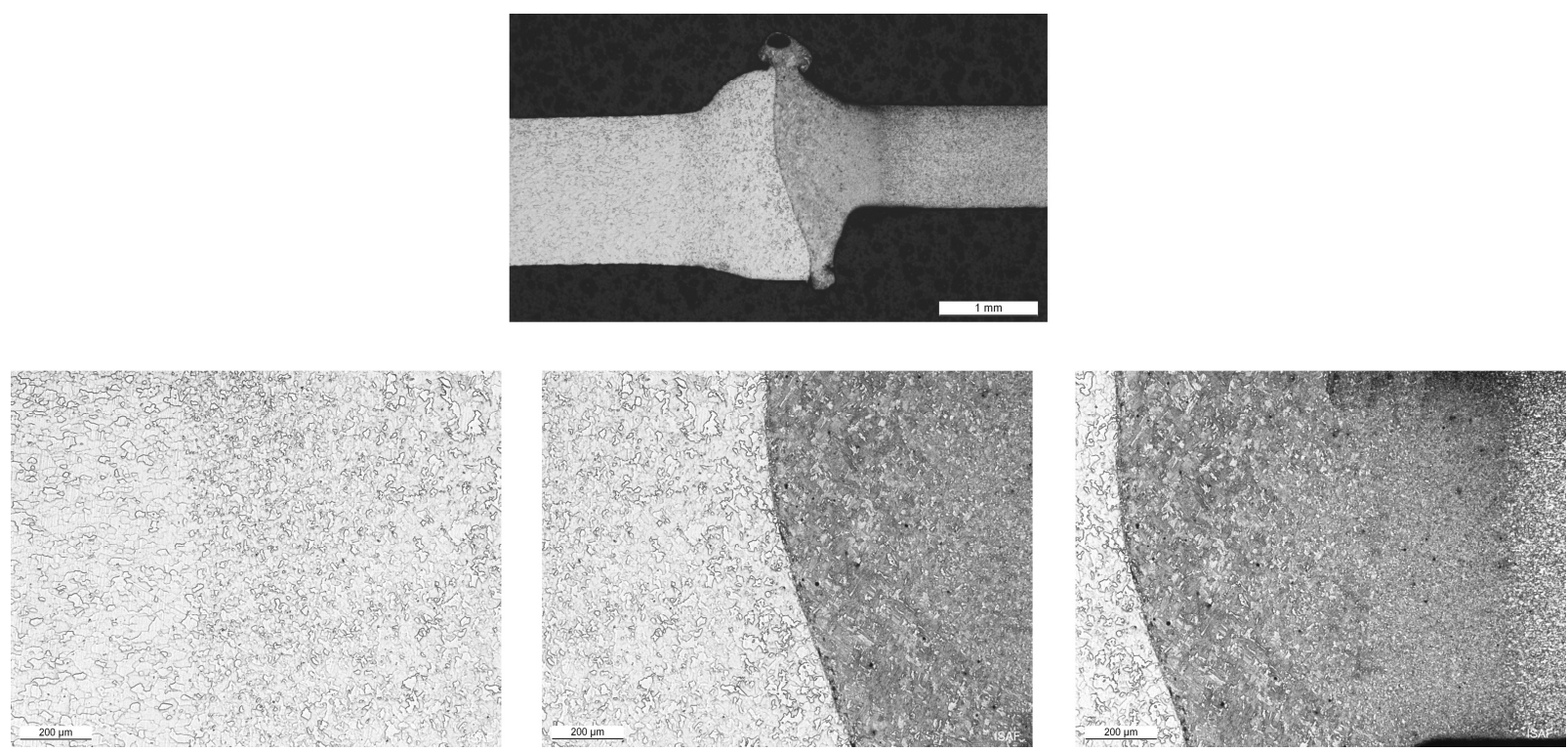

Fig. 24: Structure of a high-frequency-welded joint of 1.0338 and 1.0936 (parameter set 5)

Dissimilar joints 1.0338-1.0338 HF. The structure of the welded specimens is purely ferritic. The edge zones towards the parent material show a fine ferrite structure that turns into a more coarsegrained ferrite structure towards the middle of the joining zone. Due to the upsetting process, the fusion line is not visible.
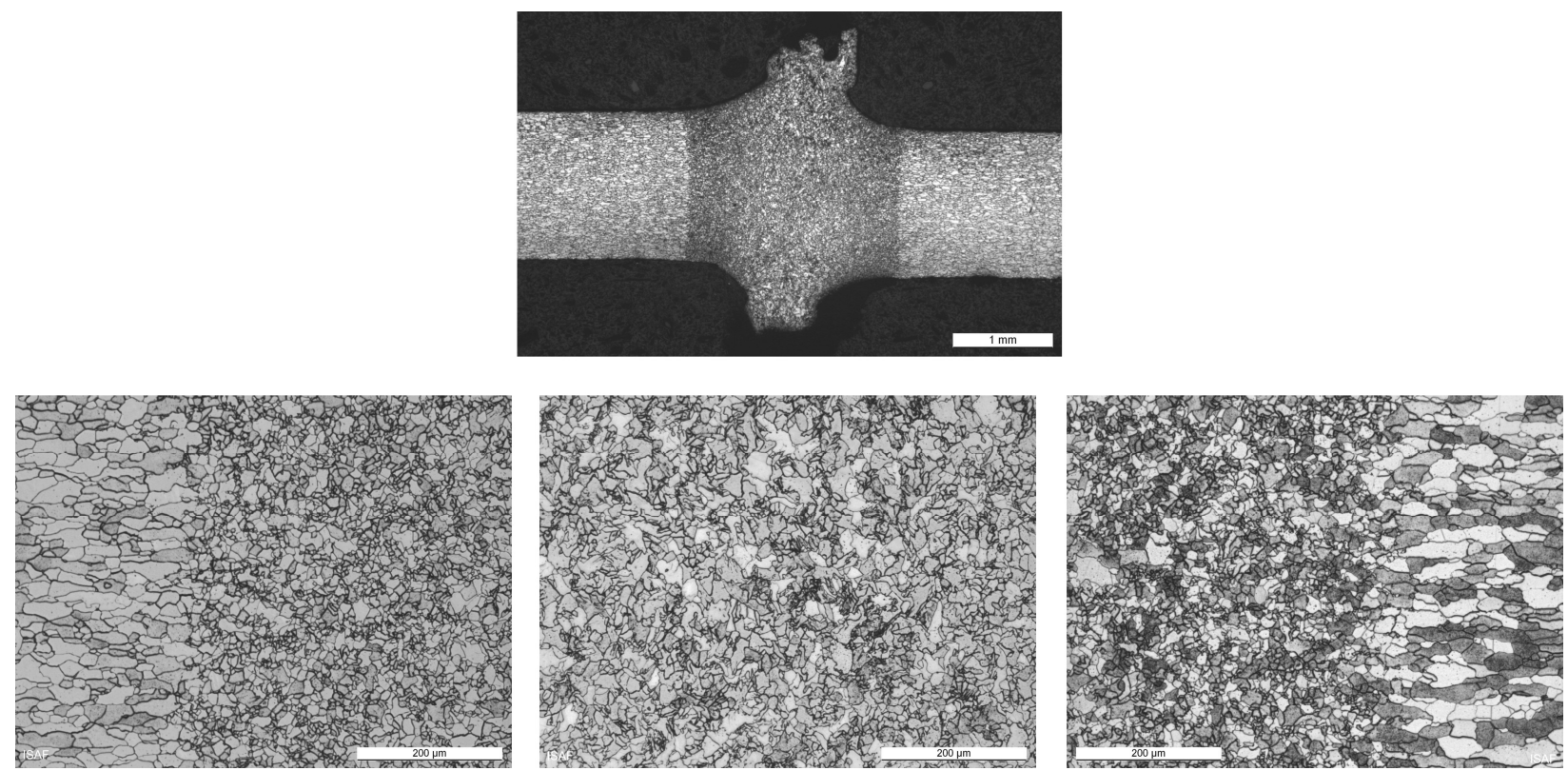

Fig. 25: Structure of a high-frequency-welded joint of 1.0338 and 1.0338 (parameter set 6) 
Table 8: Structure-related summary

\begin{tabular}{|c|c|c|c|c|c|c|}
\hline $\begin{array}{l}\text { Parameter } \\
\text { set }\end{array}$ & Material & PM 1 & HAZ 1 & WD & HAZ 2 & PM 2 \\
\hline 1 & $\begin{array}{c}1.0338- \\
1.4301\end{array}$ & Ferrite & $\begin{array}{l}\text { Ferritic fine- } \\
\text { grained zone, } \\
\text { coarse- } \\
\text { grained zone }\end{array}$ & $\begin{array}{l}\text { Austenitic cast } \\
\text { structure }\end{array}$ & $\begin{array}{c}\text { Austenite, } \\
\text { solidification } \\
\text { structure with a pasty } \\
\text { fusion line }\end{array}$ & $\begin{array}{l}\text { Austenitic with } \\
\text { twinning }\end{array}$ \\
\hline 2 & $\begin{array}{c}1.0338- \\
1.0936\end{array}$ & Ferrite & $\begin{array}{l}\text { Ferritic fine- } \\
\text { grained zone, } \\
\text { coarse- } \\
\text { grained zone }\end{array}$ & $\begin{array}{l}\text { Pearlitic cast } \\
\text { structure }\end{array}$ & $\begin{array}{l}\text { Coarse-grained to } \\
\text { fine-grained } \\
\text { formation of } \\
\text { martensite and } \\
\text { bainite }\end{array}$ & $\begin{array}{c}\text { Ferrite, insular } \\
\text { martensite }\end{array}$ \\
\hline 3 & $\begin{array}{c}1.0338- \\
1.0936\end{array}$ & Ferrite & $\begin{array}{l}\text { Ferritic fine- } \\
\text { grained zone, } \\
\text { coarse- } \\
\text { grained zone }\end{array}$ & $\begin{array}{l}\text { Pearlitic cast } \\
\text { structure }\end{array}$ & $\begin{array}{l}\text { Coarse-grained to } \\
\text { fine-grained } \\
\text { formation of } \\
\text { martensite and } \\
\text { bainite }\end{array}$ & $\begin{array}{l}\text { Ferrite, insular } \\
\text { martensite }\end{array}$ \\
\hline 4 & $\begin{array}{c}1.0312- \\
1.0936\end{array}$ & Ferrite & $\begin{array}{l}\text { Ferritic fine- } \\
\text { grained zone, } \\
\text { coarse- } \\
\text { grained zone }\end{array}$ & $\begin{array}{l}\text { Pearlitic cast } \\
\text { structure }\end{array}$ & $\begin{array}{l}\text { Coarse-grained to } \\
\text { fine-grained } \\
\text { formation of } \\
\text { martensite and } \\
\text { bainite }\end{array}$ & $\begin{array}{c}\text { Ferrite, insular } \\
\text { martensite }\end{array}$ \\
\hline 5 & $\begin{array}{c}1.0338- \\
1.0936\end{array}$ & Ferrite & $\begin{array}{l}\text { Ferritic fine- } \\
\text { grained zone, } \\
\text { coarse- } \\
\text { grained zone }\end{array}$ & $\begin{array}{c}\text { Partly } \\
\text { dissolution and } \\
\text { reformation of } \\
\text { the grain } \\
\text { boundaries in } \\
\text { the joining } \\
\text { zone }\end{array}$ & $\begin{array}{l}\text { Martensite, small } \\
\text { proportions of } \\
\text { bainite }\end{array}$ & $\begin{array}{l}\text { Ferrite, insular } \\
\text { martensite }\end{array}$ \\
\hline 6 & $\begin{array}{l}1.0338- \\
1.0338\end{array}$ & Ferrite & $\begin{array}{l}\text { Ferritic fine- } \\
\text { grained zone, } \\
\text { coarse- } \\
\text { grained zone }\end{array}$ & $\begin{array}{c}\text { Ferrite, no } \\
\text { distinct joining } \\
\text { line }\end{array}$ & $\begin{array}{l}\text { Ferritic coarse- } \\
\text { grained zone, fine- } \\
\text { grained zone }\end{array}$ & Ferrite \\
\hline
\end{tabular}

Laser-optical strain measurement for local strain determination. In order to determine the locally resolved strain behavior in selected weld seams, the laser-optical strain measurement (ESPI) was used. This process enables the determination of the strain behavior in the weld seam area of joined flat-bar tensile test specimens with transverse seams. The Institute of Welding and Machining uses the Dantec Dynamics GmbH Q.100 laser-optical strain sensor. The mode of operation of this sensor is based on the laser speckle interferometry.

The laser speckle effect is based on the diffuse scattering of monochromatic light on rough surfaces. The surface to be surveyed is illuminated with coherent and monochromatic light. The light that is reflected on the surface of the object is recorded with a camera. The laser speckle interferences are caused by the reflection of the coherent light at different angles. As a result, the light spreads randomly in space, which in turn leads to a superposition of the wave fronts.

The surface deformation is captured in all directions of space. The total deformation of the component consists of the individual deformation images of the three axes. The measured deformations are always referred to an initial state. 
In order to determine the surface points in space, it must be ensured that the laser beam can illuminate every point on the surface of the measurement object. The sensitivity of the measuring system requires an interference-free measurement environment as well as protection against external vibrations.

The DANTEC Q100 3D-ESPI system consists of a laser light source with a wavelength of $780 \mathrm{~nm}$ and a CCD camera. The representation and evaluation of the measurement data are realized with the aid of a PC and the software Istra Micro Star, version 2.4.1. Table 9 shows the technical data of the measuring system.

Table 9: Technical data of the Q-100 measurement system

\begin{tabular}{|c|c|}
\hline Data sensor & Q100 \\
\hline Measurement surface & $36 \times 27 \mathrm{~mm}^{2}$ \\
\hline Measuring sensitivity Deformation: & 0.03 to $0.1 \mu \mathrm{m}$ \\
Elongation: & $5 \times 10^{-6}$ to $20 \times 10^{-6}$ \\
\hline Camera resolution & $768 \times 576$ pixels \\
\hline Working distance & 27 to $40 \mathrm{~mm}$ \\
\hline Sensor dimensions & $54 \times 54 \times 59$ \\
\hline Sensor weight & approx. $370 \mathrm{~g}$ \\
\hline Laser class & 1 \\
\hline Laser power & $50 \mathrm{~mW}$ \\
\hline
\end{tabular}

The system measures the surface deformation and strain of the welded flat-bar tensile test specimens in all three directions of space. The deformation is induced with the aid of the Schenk-Trebel RSA100 universal materials testing machine. The total test load per specimen is approximately $4000 \mathrm{~N}$ and, therefore, it is already in the plastic deformation range. Due to the measuring sensitivity of the system, segmentation into measurement intervals of up to $50 \mathrm{~N}$ became necessary. The total deformation of the welded flat-bar tensile test specimens was determined based on the corresponding individual measurements.

Apart from the total deformation with a test load of $4000 \mathrm{~N}$, the deformation in the elastic range was also studied in a load range between $500 \mathrm{~N}$ and $1500 \mathrm{~N}$. For this purpose, the measuring software enables the manual selection of deformation images (e.g. deformation images 20 to 40). In this case, the initial state of the measurement is the first deformation image that is selected.

The distance between the objective lens of the camera and the flat-bar tensile test specimens is defined by a spacer and is fixed at $32 \mathrm{~mm}$. It was not changed during the measurement. This distance results in a measurement area of approximately $27.5 \times 20 \mathrm{~mm}^{2}$. This is why the strain area of the flat-bar tensile test specimens is limited to $18 \mathrm{~mm}$ as shown in the illustration.

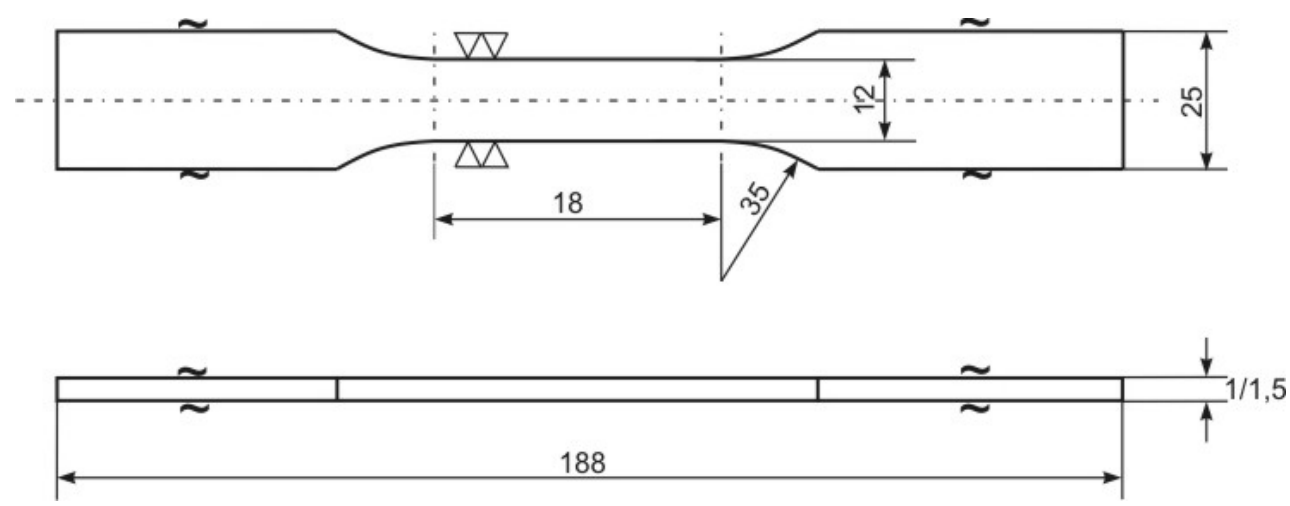

Fig. 26: Flat-bar tensile test specimen for the laser-optical strain measurement 
The reinforcement of the weld seam is worked off prior to the test in order to achieve a uniform specimen cross-section, so that every point on the specimen surface will be reached by the laser beam of the measuring system. The shiny metallic surface of the flat-bar tensile test specimens is treated with a thin color coat (developer spray for dye penetration tests) in order to prevent the measurement area from being overexposed. In addition, the entire test set-up is darkened in order to shield it against ambient light. The aim of the laser-optical strain measurement is the loaddependent determination of the locally resolved strain in the weld seam in order to derive the possible material properties, such as the modulus of elasticity.

As a result of technical problems, only the ESPI test results of the second parameter set will be presented in the following. The strain behavior of a MAG-welded joint of $1.0338(1.5 \mathrm{~mm})$ and $1.0936(1.0 \mathrm{~mm})$ was analyzed.

Prior to the test, the flat-bar specimens were loaded with approximately $500 \mathrm{~N}$ and then relieved again in order to avoid the setting of the chucking tool at the start of the test as well as to ensure a defined start for all of the specimens. The weld seam is aligned centrally in the camera frame. Prior to the measurement, the outline of the flat-bar test specimen must be defined in the boundary editor of the measuring software, and the measuring range is marked with a cross. As a result of the load, interference fringes form on the specimen surface (see Fig. 27). When the camera is triggered, the phase images are filmed from four different directions. For every load interval, the four phase images in turn form the deformation on the surface of the test object.
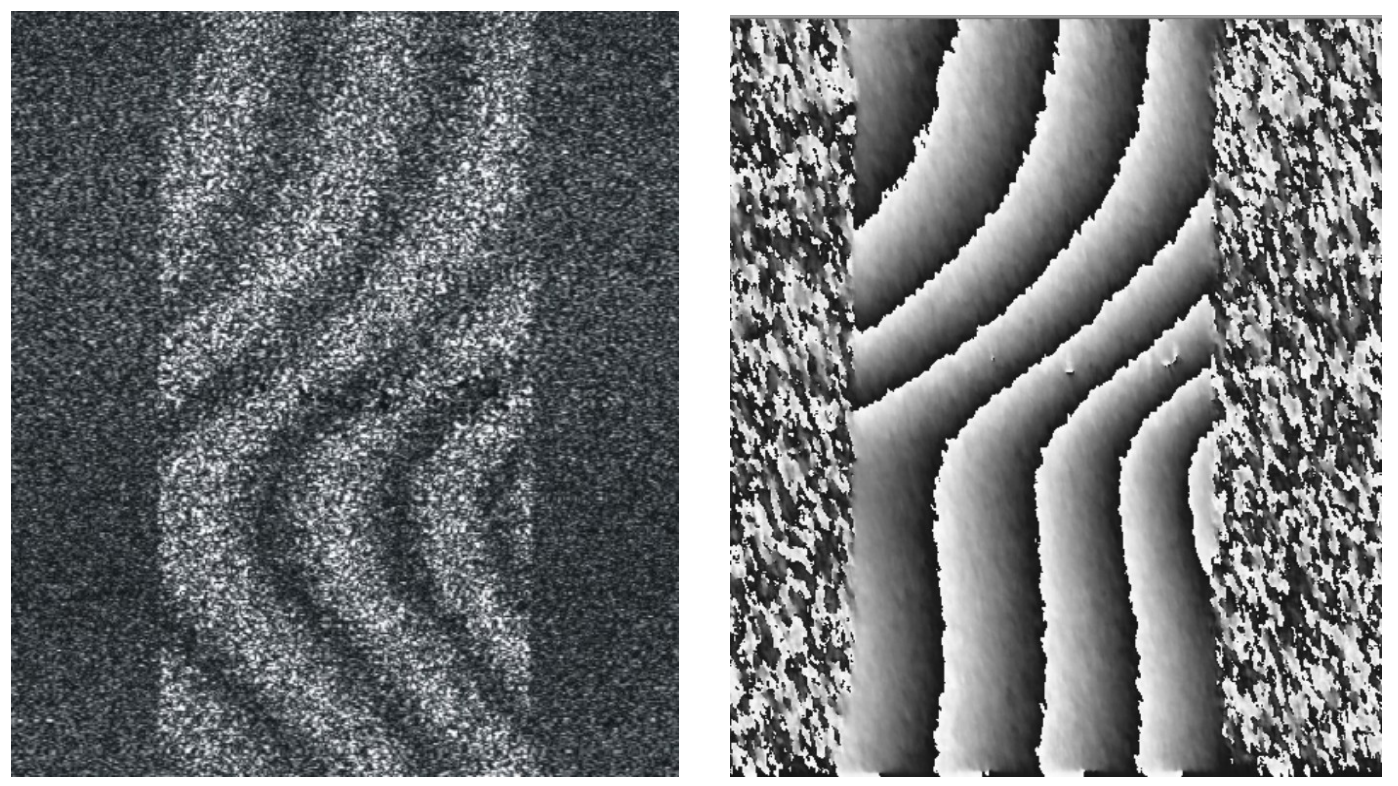

Fig. 27: Interference fringes (left) and a phase image (right)

Fig. 28 shows the different strains of two measurements in the areas of the flat-bar test specimen, which were produced with the aid of parameter set 2 . With $4000 \mathrm{~N}\left(222 \mathrm{~N} / \mathrm{mm}^{2}\right)$, the test load is above the yield point of the lower-strength material 1.0338. The higher strain in the weld seam and in the 1.0338 parent material, which is also the point of failure of the flat-bar tensile test specimens, is clearly visible. 

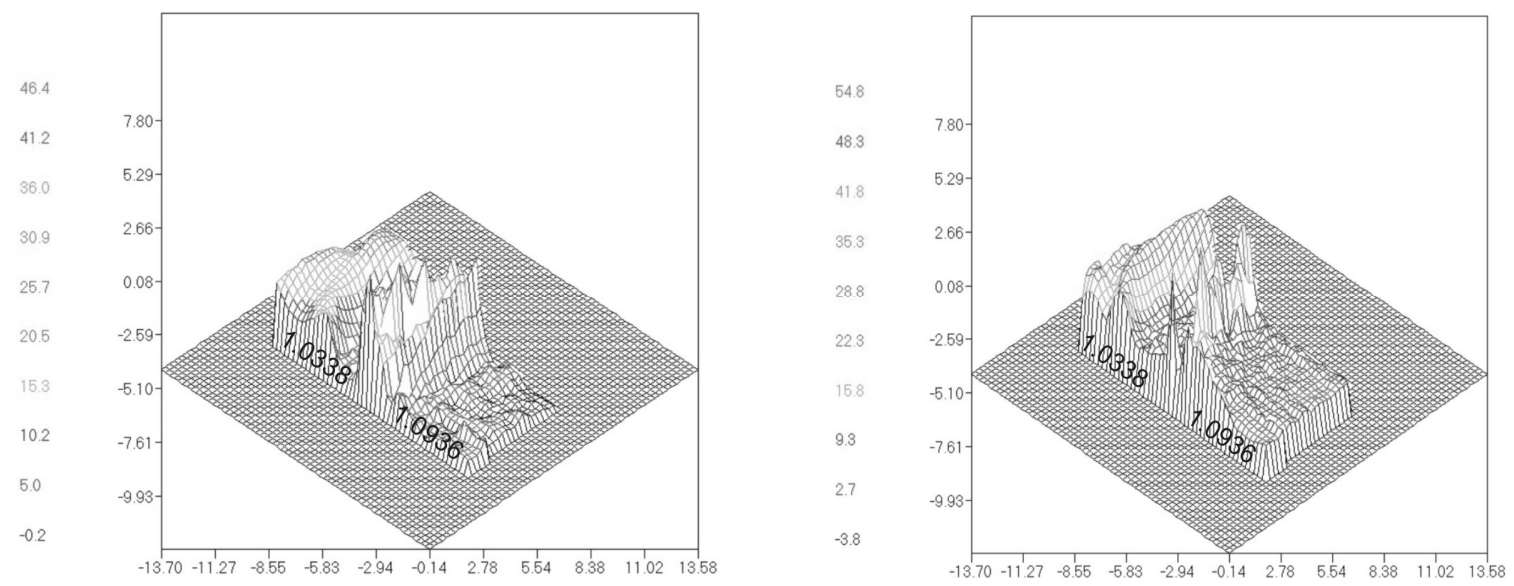

Fig. 28: Strain distribution above the yield point, parameter set 2

The determined strains in the test load, which ranges between $500 \mathrm{~N}$ and $1500 \mathrm{~N}\left(28 \mathrm{~N} / \mathrm{mm}^{2}\right.$ to $83 \mathrm{~N} / \mathrm{mm}^{2}$ ), are shown in Fig. 24. This test load range is below the yield point of the lower-strength material 1.0338 and, therefore, it is in the elastic range. Clear strain areas in the weld seam and in the 1.0338 parent material, as they were found in Fig. 24, cannot be seen in this case. In Fig. 29, the parent materials can be distinguished by their different strain proportions. The strain in the weld seam area is similar to that of the parent materials
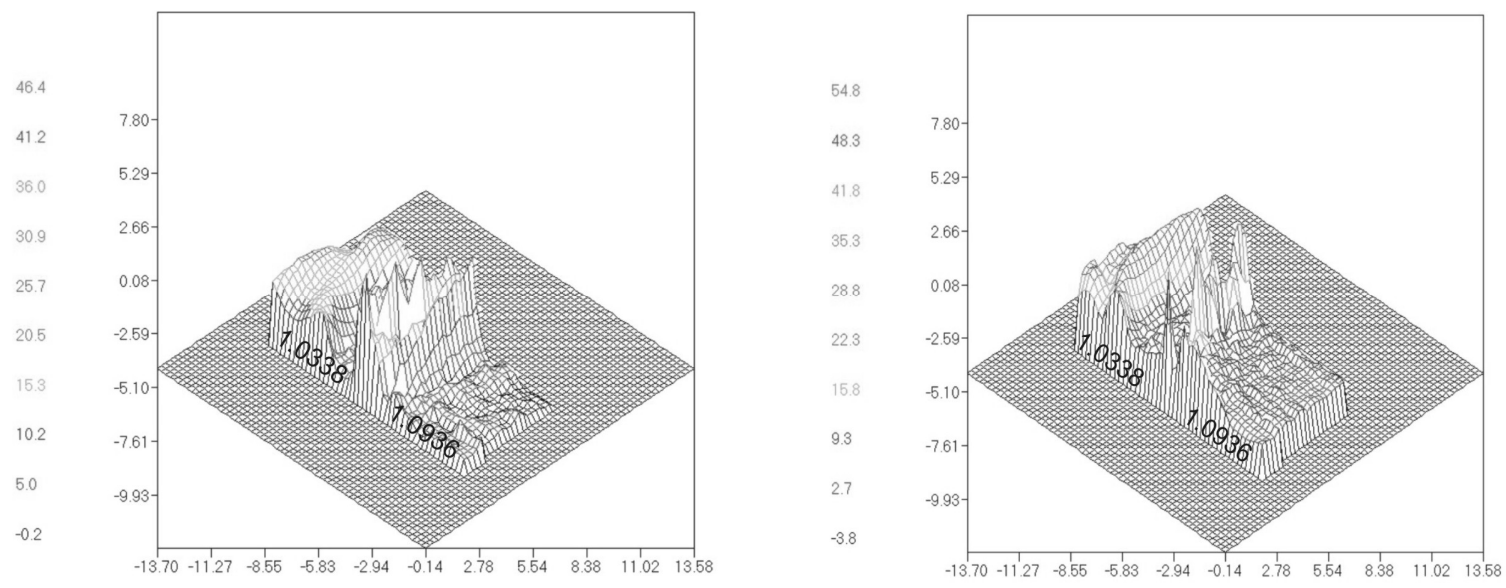

Fig. 29: Strain distribution below the yield point, parameter set 2

The knowledge concerning the deformation in the various specimen zones and the associated load input that causes this deformation enable the calculation of the modulus of elasticity $\mathrm{E}$ :

$$
\sigma=\frac{F}{S}=E \cdot \varepsilon \rightarrow E=\frac{F}{S \cdot \varepsilon}
$$

The boundary dimensions of $10 \mathrm{~mm} \times 18 \mathrm{~mm}$, which were defined with the aid of the boundary editor, correspond approximately to the strain area that is defined by the specimen geometry. The strains that were determined with the aid of the software can be exported in the form of an ASCII file, for example, for further processing in Excel. The result is a matrix of $256 \times 256$ pixels, with one strain value assigned to every pixel. As a result of the boundary definition, only a sector of approximately $90 \times 181$ pixels will be evaluated, which corresponds exactly to the strain area of the flat-bar test specimens. 


\section{Software implementation of the systematic FED design approach}

Introduction of the FED system. In order to support the design engineer, the FED process is implemented and realized in the form of software. The reason for the implementation in the form of software is the extensive amount of information that goes far beyond what any human being can handle. The CES Selector by Granta Design, for example, includes approximately 3,700 materials, which is only a small fraction of all the existing materials. If one now assumes a component that is divided into only two functional elements, a total of 3,700 materials lead to more than 7 million possible material combinations. This number would be significantly reduced because of the specified requirements, but there would still be far more combinations than the design engineer can rate for their relevance in any reasonable time. First and foremost, the amount of combinations must be reduced to a useful number, which would be expecting too much from any human being. This is why an essential part of the FED system is a database of materials and their characteristic values. Another database stores information regarding which characteristic material values characterize certain requirements. The requirements in turn result from the description of the function of a functional element. The user uses a graphical user interface (GUI) in conjunction with the FED system that retrieves its information from the two databases. Fig. 1 shows the layout of the FED system.

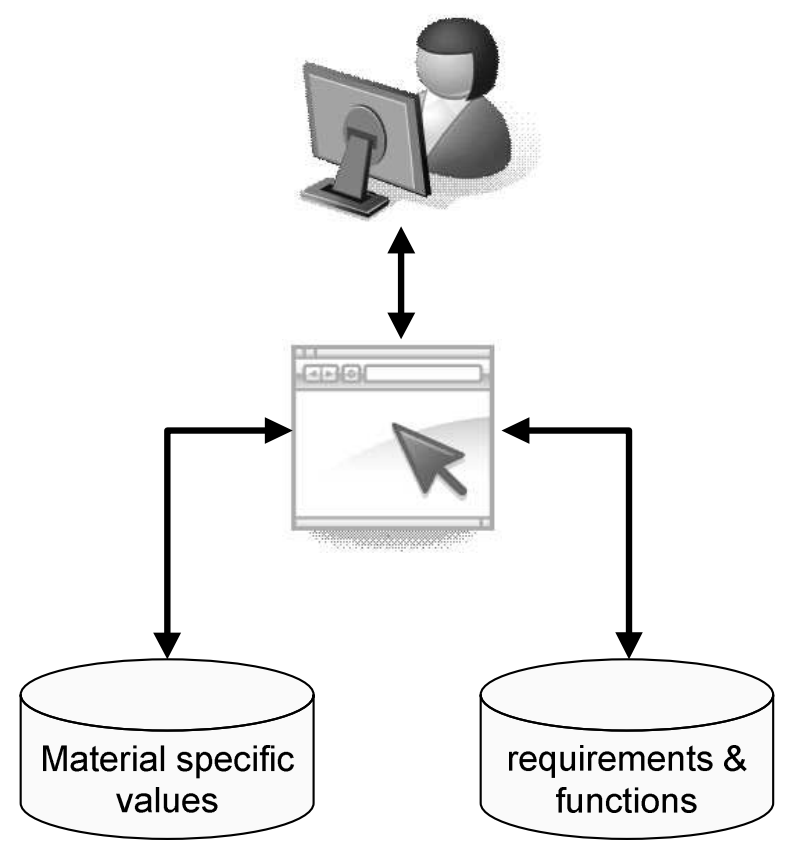

Fig. 30: Layout of the FED system

The data are stored in two separate databases in order to enhance the performance. It can be assumed that further developments of the FED system will include significantly more materials and characteristic values than is now the case. During the work with the FED system and the creation of functional elements and interfaces, the database containing the requirements and functions is addressed much more often than the material database, which is not needed until for the final search for potential materials. This is also the reason as to why the information is stored in two separate databases. 
Sequence of the FED system. The sequence of the FED system follows the FED reference process. In this case, however, the reference process is repeatedly interrupted in the FED system when the system waits for input by the user or when it retrieves new information. This sequence is shown in Fig. 31. The sequence diagram shows the interactions between the user and GUI as well as the enquiries addressed to the two databases.

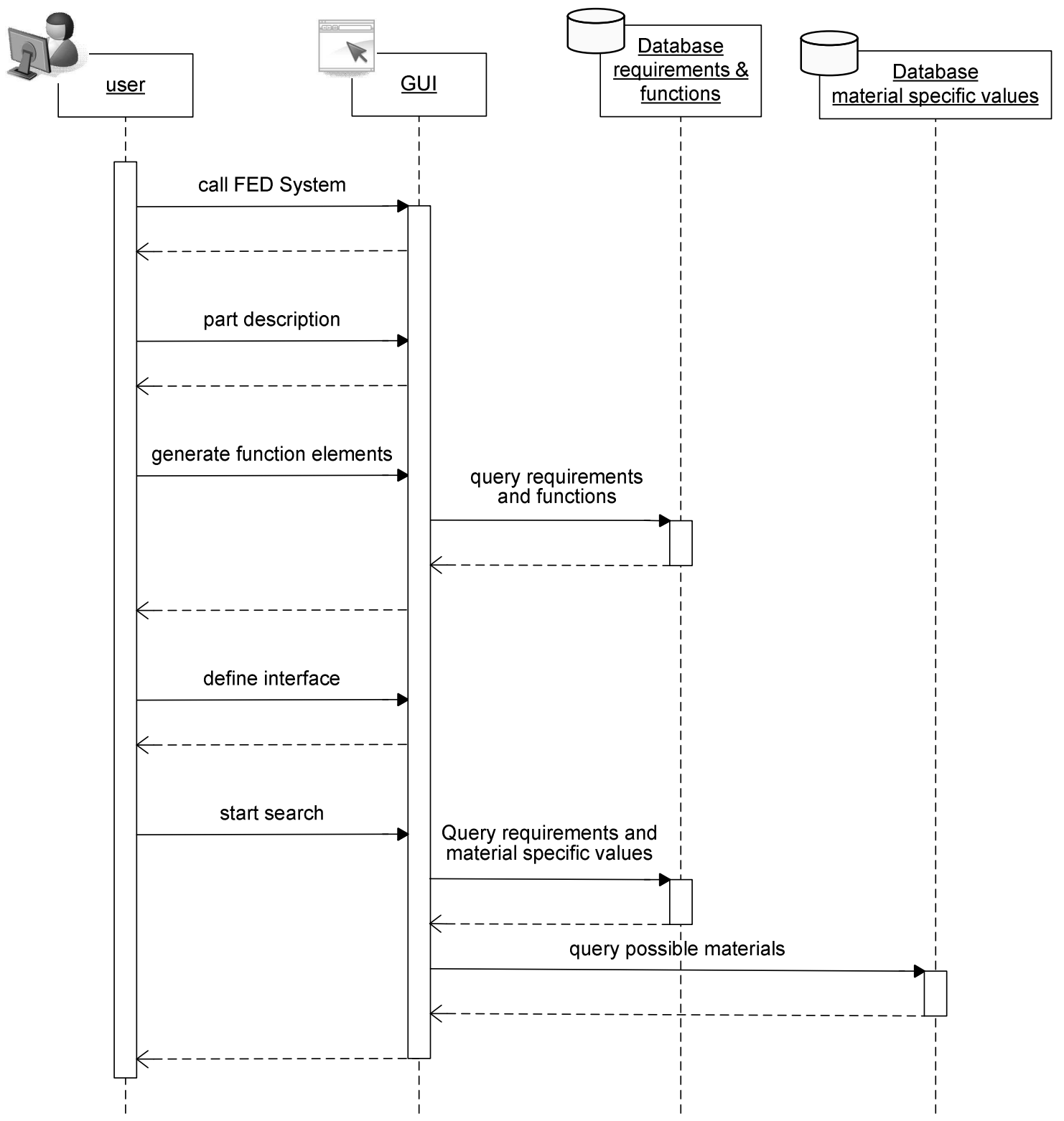

Fig. 31: Sequence diagram of the FED system

In accordance with the FED reference process, the user first creates the component and then the individual functional elements. The first database access takes place during the creation of the functional elements. The system enquires as to which requirements are a part of the selected function of a functional element. This is indicated accordingly in the GUI. After the definition of the interfaces between the functional elements, the search process is started. In a first step, information is collected as to which material properties characterize a requirement. Once the material properties have been defined, materials are sought and selected based on the conditions that were specified by the user.

The screenshot in Fig. 32 provides an impression of the FED system. The screenshot shows the symbolic representation of a component with three functional elements. In the middle, there is a 
dialog box for the description of a functional element, and on the right hand side of it there is a dialog box for the characterization of the connection between two functional elements.

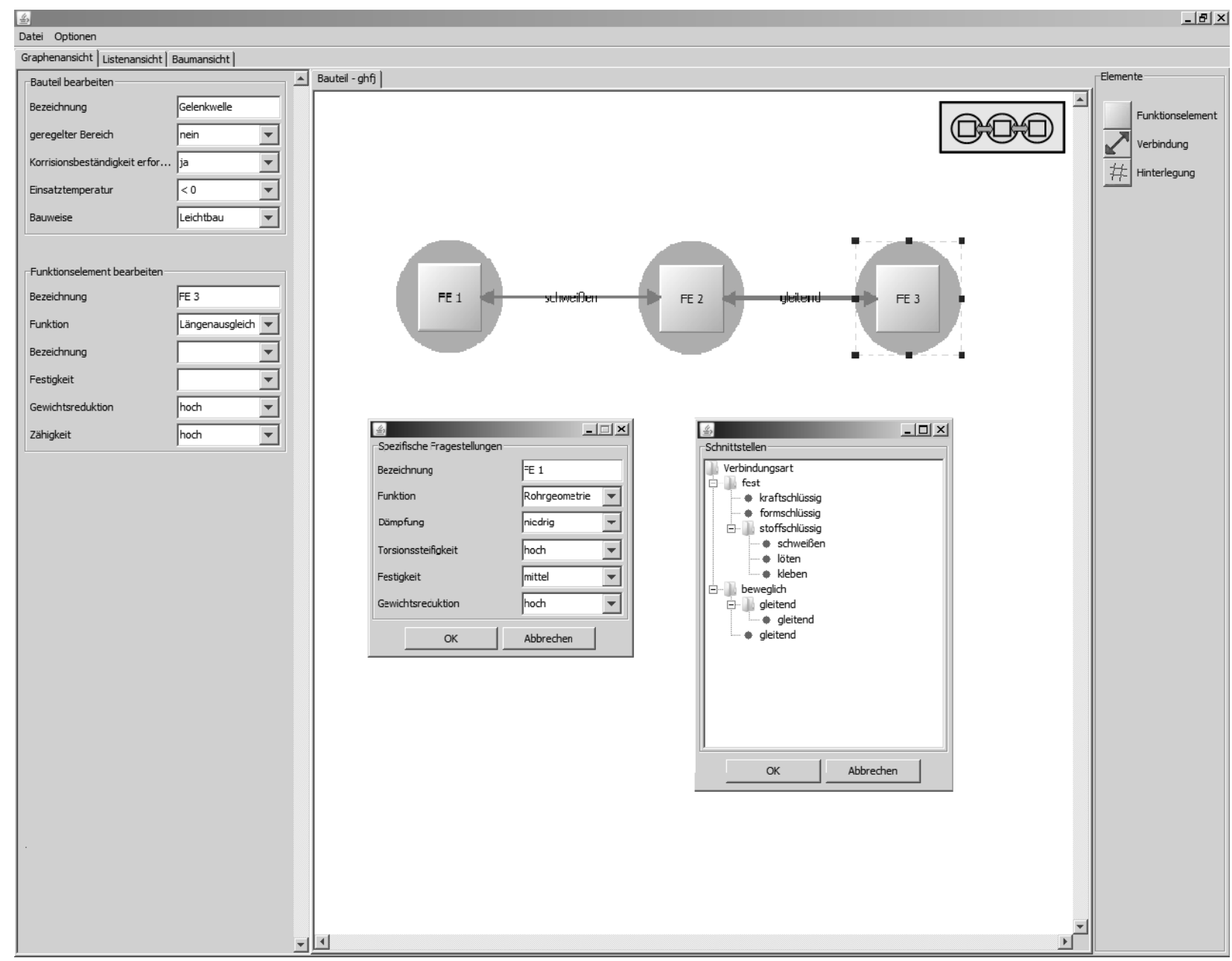

Fig. 32: Original screenshot of the FED system

Distinction from an expert system. Since an FED system uses the knowledge of experts, design engineers, joining engineers, and material experts, one might presume that it is an expert system. This is not the case, however, since the FED system lacks some of the essential features of an expert system. According to [39], an expert system is a "program system that stores and collects 'knowledge' about a special field, draws conclusions from this knowledge, and offers solutions for concrete problems in this special field".

The FED system also collects knowledge that can perfectly well be considered as expert knowledge. This knowledge is also used then to generate solutions, but there is one important difference with regard to an expert system. First of all, it must be noted that such a system is characterized by various different components, which are listed below and shown in Fig. 33:

- knowledge base

- dialog with the user

- explanatory components for the verification of the solution that is found

- changing knowledge

- solution-finding

The next steps will focus on increasing the level of refinement of the search for, and selection of, suitable materials. At present, all of the search parameters must be fulfilled. As a consequence, the resulting solution set is very small or even empty. In order to change this, the search procedure is to be extended by fuzzy logic. This logic will enable statements of the kind that an element is part of a 
set only to a certain extent [40]. Such a system will be able to deliver results that fulfill the search request only to a certain extent. This means that certain search requests will either be ignored or considered with a lower degree of precision. This is actually not a disadvantage, since there are cases where an optimum material simply does not exist or cases where a not entirely optimum material can be transformed into an optimum material by a clever design.

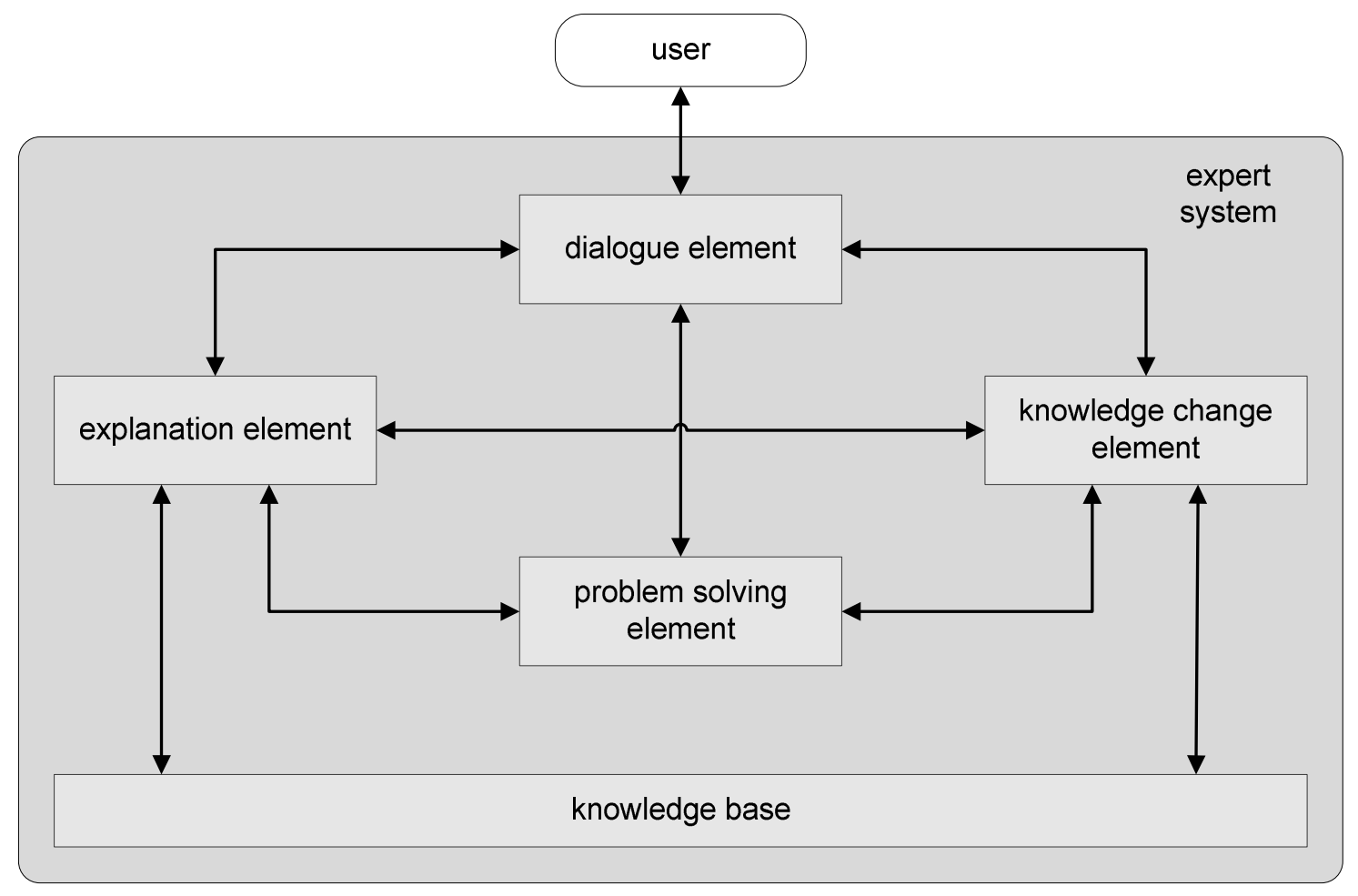

Fig. 33: Layout of an expert system according to [40]

The FED system, however, does not change its knowledge base itself and it does not generate any solution suggestions itself. This is carried out by the user. In addition, it does not include any explanatory component, since the final solution is to be selected by the user. The FED system only offers a selection of potential solutions, for this reason it is not an expert system.

\section{Summary}

Materials with locally adapted properties in connection with manufacturing-related boundary conditions can only be applied in the course of a systematic design process, if a systematic design method is available. The finite element design method is used in order to enable the user to fully benefit from the potentials of materials with locally modified properties with the aid of local requirement matrices in conjunction with local material properties.

The structuring of components into functional elements with definable requirements as well as the specification of interfaces that describe the interconnection of the individual functional elements provide an opportunity for drawing conclusions concerning the required local material properties.

The exemplary examination of welded material combinations can be used as a model for integrating and processing targeted material properties from a metallurgical, physical, and chemical point of view within the FED system. 


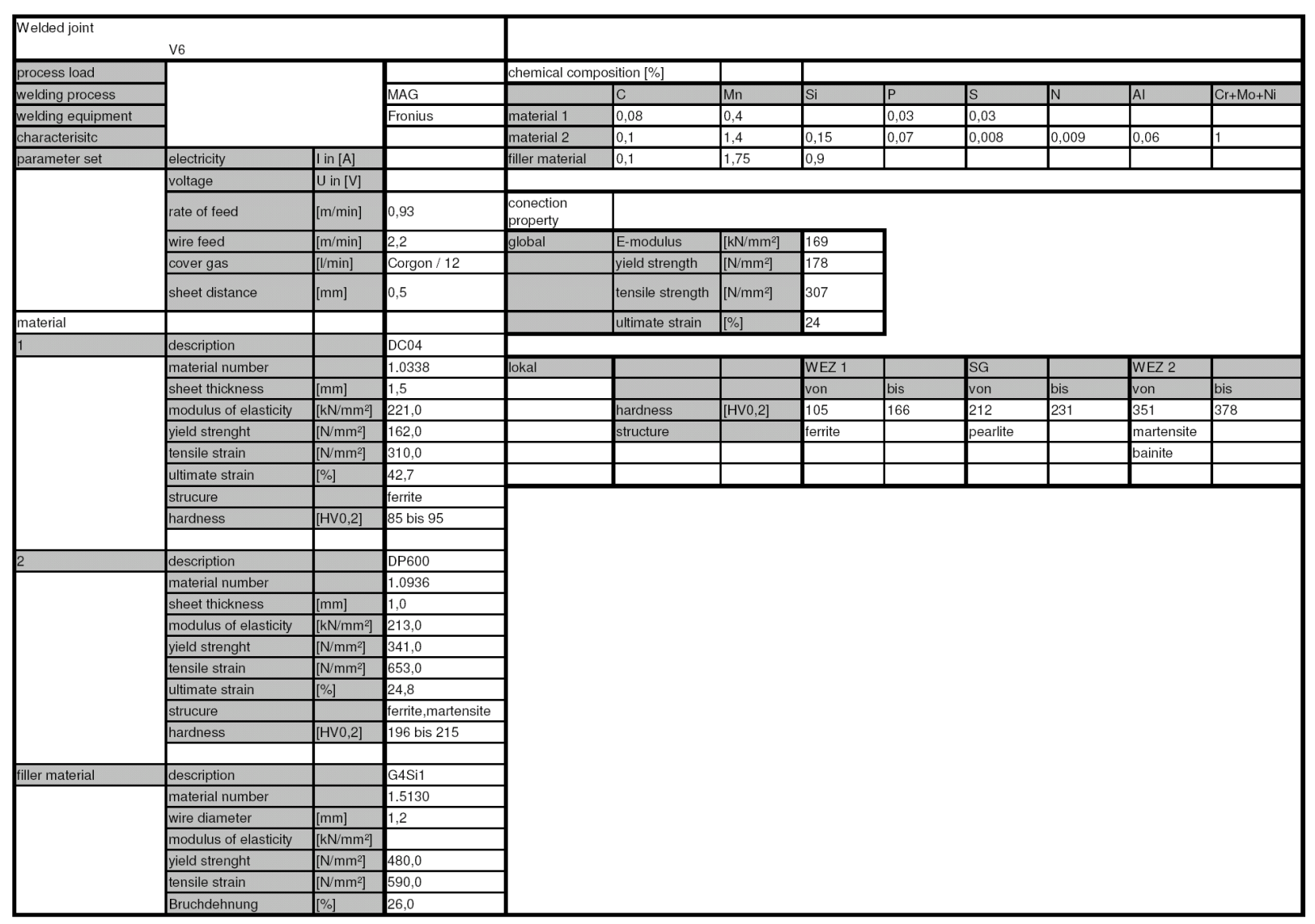

Fig. 34: Data sheet with joining properties

The high level of complexity of the information, which is due to the large number of materials and the resulting material properties, requires software support for the FED system. The integration and implementation of the local material properties of the other SFB 675 sub-projects is to provide the design engineers of the future with an extensive systematic design method in the form of the finite element design approach. This method will make full use of the potential of the various materials and manufacturing processes.

Another future step is to examine as to whether the data of the FED system can be transferred into other applications in the product development or design. Other applications in this context may be weld seam simulations or FEM applications, since both simulation applications require numerical data about the materials or weld seams that are stored in the FED system.

Within the integration and realization of materials with locally adapted properties which are researched by the subprojects of the collaborative research centre 675 , in the future an extensive systematic of design will be disposed to the technical designer in form of the FED-system, which considers the potential of design, local material properties as well as manufacturing aspects optimally. The FED-systematic of design is to be seen as an integrated component of the entire methodical construction procedure. 


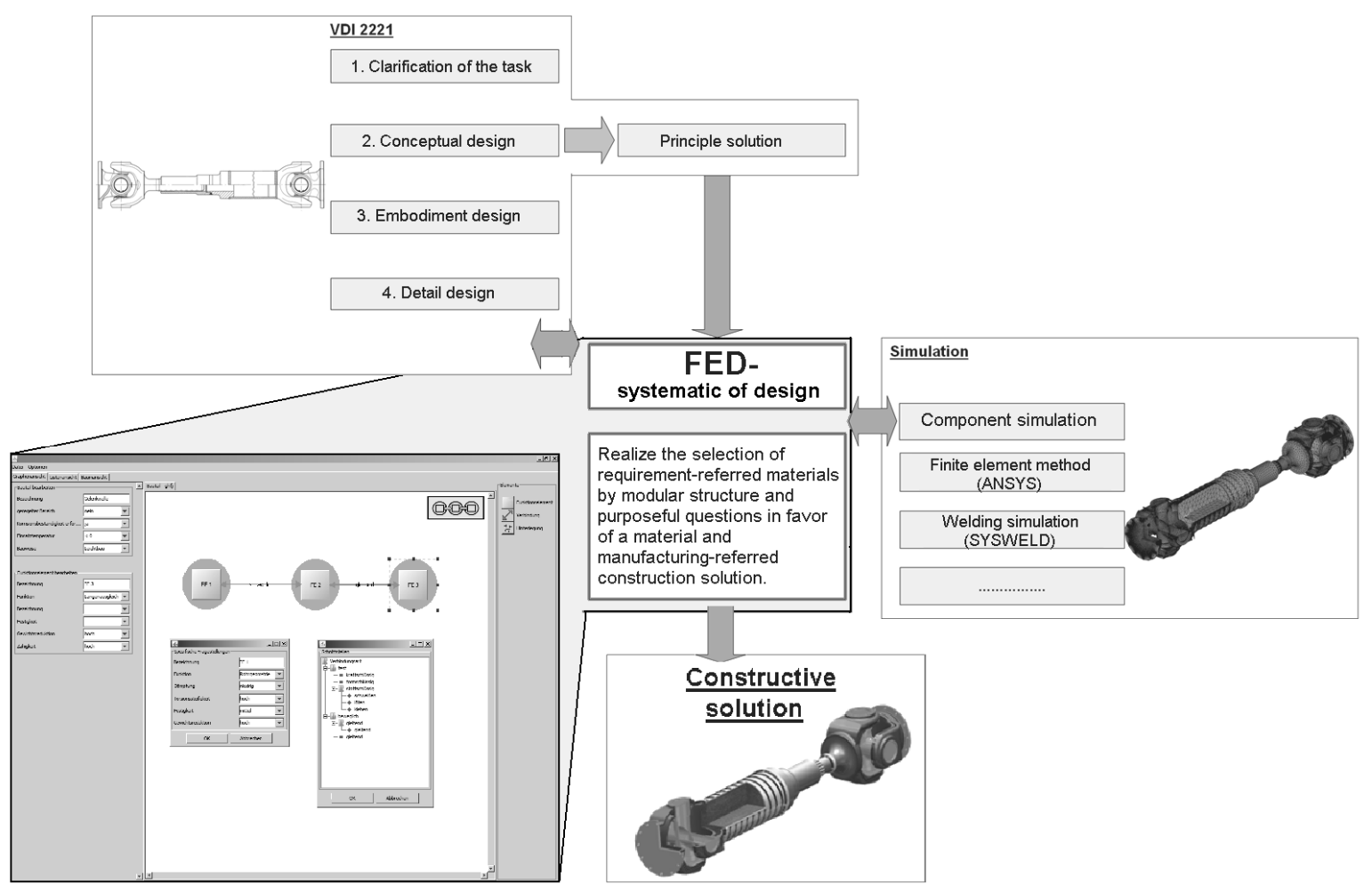

Fig. 35: Finite Element Design as an integrating component of the design-process

\section{References}

[1] G. Meschut, M. Goede: Neue Werkstoff- und Bauweisenkonzepte im Fahrzeugbau Herausforderungen für thermische und wärmearme Fügeverfahren; Fügen im Fahrzeugbau, Bb. 9. Internationales Aachener Schweißtechnik Kolloquium, 29. - 30.06.2004; pp. 37 - 48.

[2] C. Fritzsche, M. Schmidt: Hochfrequenzschweißen - Stand und Anwendungen, Konferenzeinzelbericht DVS-Berichte, Band 213, (2001), pp. 87-92, DVS Verlag Düsseldorf.

[3] A. Lohrengel, G. Schäfer, V. Wesling: Design strategies fort he development of high strength coupling elements from requirement optimized composite materials, Creation of High-Strength Structures and Joints by Setting up Local Material Properties, trans tech publications, StafaZurich, (2007)

[4] A. Lohrengel, S. Bessling, K. Stahr, V. Wesling, P. Echtermeyer: Finite Elemente Desgin (FED) - a new approach for material and manufacturing based design rules, Virtual International Conference on Innovative Production Machines and Systems (IPROMS 2009), The Internet, (2009), Whittles Publishing (Scotland) (2009).

[5] A. Lütkepohl: Werkstoffgerechte Lösungsfindung durch anforderungsgetriebene Konstruktionsmethodik, IMW - Institutsmitteilung (2006), Nr. 31.

[6] M. Reuter: Methodik der Werkstoffauswahl, Der systematische Weg zum richtigen Material, Carl Hanser Verlag München, (2007)

[7] A. Lohrengel, G. Schäfer, V. Wesling: Iterative loop to include material an manufacturing information in an early design stage, Virtual International Conference on Innovative Production Machines and Sytems (IPROMS 2007), The Internet, 2nd-13th July 2007, Whittles Publishing (Scotland) (2007). 
[8] A. Gutmann: Werkstoffgerechte Lösungsfindung - funktionäre Werkstoffe im Konstruktionsprozess, IMW - Institutsmitteilung (2005), Nr. 30.

[9] S. Penschke, A. Große, F. Heinen: Ansätze zur parallelen Gestaltung von Produkten und Fertigungsprozessen, IMW - Institutsmitteilung (1996), Nr. 21.

[10]S. Bessling, P. Echtermeyer, T. Korte: Finite Elemente Design, IMW - Institutsmitteilung (2008), Nr. 33.

[11]M.F. Ashby: Materials Selection in Mechanical Design, Das Original mit Übersetzungshilfen, 1. Aufl.; Spektrum Akademischer Verlag München, (2007)

[12]P.P. Dargie: MAPS 1: Computer Aided Design for preliminary material and manufacturing process selection, Trans. ASME J. Mech. Design; pp. 104, 126 - 136, (1982)

[13]A. Große: Interdisziplinäre Werkstoffauswahl durch Aufbau eines Material Data Mart, Dissertation TU Clausthal, ISBN: 978-3-89720-463-0, Papierflieger Verlag, (2001)

[14]Pohle, C.: Schweißen von Werkstoffkombinationen, DVS-Verlag Düsseldorf: (1999)

[15] O. Hahn, S. Brüdgam, G. Meschut: Fügesystemoptimierung zur Herstellung von Mischbauweisen aus Kombinationen der Werkstoffe Stahl, Aluminium, Magnesium und Kunststoff, Paderborn, Universität, Fachbereich Maschinenbau/Werkstoff- und Fügetechnik, Abschlussbericht (2003)

[16]S. Anik, L. Dorn: Schweißeignung metallischer Werkstoffe, 1. Auflage, DVS-Verlag Düsseldorf, (1995)

[17]N.N.: Fügetechnik: Schweißtechnik, 6. Auflage, Düsseldorf, DVS-Verlag Düsseldorf, (2004)

[18]H. Fahrenwald, V. Schuler: Praxiswissen Schweißtechnik, 2. Auflage, Wiesbaden, Vieweg \& Sohn Verlag, (2006)

[19]U. Dilthey: Schweißtechnische Fertigungsverfahren 2: Verhalten der Werkstoffe beim Schweißen, 3. Auflage, Berlin, Springer-Verlag, (2005)

[20]A. Donges, R. Noll: Lasermesstechnik, Grundlagen und Anwendungen, 1. Auflage, Heidelberg, Hüthing Buch Verlag GmbH, (1993)

[21]N.N.: Fast Determination of Full Field Strain and Stress, Produktbroschüre, Dantec Dynamics GmbH, Ulm, www.dantecdynamics.com

[22]A. Ettemeyer, S. Keil: Spannungen in kritischen Bauteilen flächenhaft messen und analysieren, Zeitschriftenaufsatz: Maschinenmarkt, Band 106, Heft 49, pp. 58-60,63 (2000)

[23]Siebert, T.; El-Ratal, W.; Ettemeyer, A.: Combine simulation and experiment in automotive testing with ESPI measurement, Zeitschriftenaufsatz: Experimental Techniques, pp. 42-47 (2002)

[24]J.A. Rayas, R. Rodríguez-Vera, A. Martínez: Medición del modulo de Young en el hule latex usando ESPI, Zeitschriftenaufsatz: REVISTA MEXICANA DE FÍSICA, Band 49, pp. 555-564 (2003)

[25]T.T. Ebenezer, P. Langehanenberg, B. Kemper: Investigation of Young's modulus of elasticity in wood using Electronic Speckle Pattern Interferometrie (ESPI), Online-Zeitschrift "DGaOProceedings" der Deutschen Gesellschaft für angewandte Optik e.V. (2006)

[26]K. KIM, H. Chang, S. Jung: Determination of Elastic modulus of thin materials by Speckle Interferometry, 17th World Conference on Nondestructive Testing, Shanghai (2008) 
[27]N. N.: Aplicación de la technical de interferometría laser electrónica ESPI (Electronic Speckle Pattern Interferometry) en la medición de tensiones y deformaciones en cordones de soldadura, Articulo Tecnico (2008)

[28]T.F. Rekersdrees: Untersuchungen zum konduktiven Hochfrequenzschweißen für die Herstellung von Platinen, Clausthal-Zellerfeld, Technische Universität, Fakultät Mathematik/Informatik und Maschinenbau, Diss., (2006)

[29]C. Ferdinand: Mise en oeuvre et caractérisation d'assemblages soudés par procédés TIG et laser de tôles d'alliages de titane réfractaires, Toulouse, 1'Institut National Polytechnique de Toulouse, Diss., (2005)

[30]U. Draugelates, A. Schram: Bestimmung der qualitätsrelevaten Werkstoff- und Prozesskenngrößen für das kombinierte Umformen und Fügen von Feinblech, Sonderforschungsbereich 362, Fertigen in Feinblech, Arbeits- und Ergebnissbericht 1. Januar 2000 bis 31. Dezember 2002, pp.83-180 (2002)

[31] Schwetje, T.: Untersuchungen zum Hochfrequenzschweißen von Konturbauteilen, ClausthalZellerfeld, Technische Universität, Fakultät für Bergbau, Hüttenwesen und Maschinenwesen, Diss., (2002)

[32]Heerde, P.: Einsatz der Speckle-Interferometrie für die Bewertung des Spannungs- und Verformungsverhaltens zur materialabhängigen Gestaltoptimierung prothetischer Konstruktionen, Universitätsmedizin Berlin, Medizinische Fakultät Charité, Diss. (2009)

[33]U. Birkel: Ein neues Verfahren zur Ermittlung des Eigenspannungszustandes am Beispiel der Scheibe mit Kreisloch mit Hilfe der Elektronischen Speckle-Pattern-Interferometrie und der Finite-Elemente-Methode, Universität Stuttgart, Fakultät Energietechnik, Diss. (2001)

[34]G. Pahl, W. Beitz: Konstruktionslehre: Methoden und Anwendung, Springer Verlag, Berlin, (2003)

[35]D. Müller: Intelligente Unterstützung für ein aufgabenorientiertes Anforderungsmanagement in der integrierten Produktentwicklung, Dissertation TU Clausthal, ISBN 978-3-8322-5860-3, Shaker Verlag, (2006)

[36]A. Lütkepohl: Einfluss des Werkstoffes auf den Konstruktionsprozess als Vorschlag zur Entwicklung einer Vorgehensweise, Dissertation TU Clausthal, ISBN 978-3-86948-034-3, Papierflieger Verlag, (2009)

[37]C. Rupp: Requirements-Engineering und -management: Professionelle, iterative Anforderungsanalyse für die Praxis, 2. Auflage, Hanser Verlag, München, (2002)

[38]B. Schienmann: Kontinuierliches Anforderungsmanagement, Prozesse - Techniken Werkzeuge, Addison-Wesley Verlag, München, (2002)

[39]H. Engesser, [Hrsg.]: Duden „Informatik“, Bibliographisches Institut \& F.A. Brockhaus AG, Mannheim (1993), Eintragungen „Künstliche Intelligenz“ und „Expertensystem“

[40]B. Biewer: Fuzzy- Methoden. Praxisrelevante Rechenmodelle und Fuzzy- Programmiersprachen, Springer Verlag Berlin, (1997) 